\title{
Unveiling the Mechanisms of Solid-State Dewetting in Solid Oxide Cells with Novel 2D Electrodes
}

\author{
Authors: Bowen Song ${ }^{\mathrm{a}^{*}}$, Antonio Bertei ${ }^{\mathrm{a}, \mathrm{b}^{*}}$, Xin Wang ${ }^{\mathrm{c}}$, Samuel J. Cooper ${ }^{\mathrm{d}}$, Enrique Ruiz-Trejo ${ }^{\mathrm{a}}$, \\ Ridwanur Chowdhurya ${ }^{a}$, Renaud Podore, Nigel P. Brandon ${ }^{a}$ \\ a Department of Earth Science and Engineering, Imperial College London, UK \\ ${ }^{b}$ Department of Civil and Industrial Engineering, University of Pisa, Italy

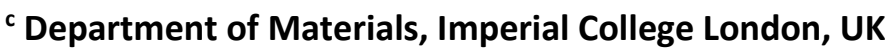 \\ ${ }^{d}$ Dyson School of Design Engineering, Imperial College London, UK \\ e ICSM, CEA, CNRS, ENSCM, University Montpellier, France \\ * Corresponding authors: antonio.bertei@unipi.it, b.song15@imperial.ac.uk
}

\begin{abstract}
During the operation of Solid Oxide Cell (SOC) fuel electrodes, the mobility of nickel can lead to significant changes in electrode morphology, with accompanying degradation in electrochemical performance. In this work, the dewetting of nickel films supported on yttriastabilized zirconia (YSZ), hereafter called 2D cells, is studied by coupling in-situ environmental scanning electron microscopy (E-SEM), image analysis, cellular automata simulation and electrochemical impedance spectroscopy (EIS). Analysis of experimental E-SEM images shows that Ni dewetting causes an increase in active triple phase boundary (aTPB) length up to a maximum, after which a sharp decrease in aTPB occurs due to Ni de-percolation. This microstructural evolution is consistent with the EIS response, which shows a minimum in polarization resistance followed by a rapid electrochemical degradation. These results reveal that neither evaporation-condensation nor surface diffusion of $\mathrm{Ni}$ are the main mechanisms of dewetting at $560-800{ }^{\circ} \mathrm{C}$. Rather, the energy barrier for pore nucleation within the dense $\mathrm{Ni}$ film appears to be the most important factor. This sheds light on the relevant mechanisms and interfaces that must be controlled to reduce the electrochemical degradation of SOC electrodes induced by Ni dewetting.
\end{abstract}

Keywords: Ni-YSZ, dewetting, in-situ environmental SEM, electrochemical impedance spectroscopy 


\section{Introduction}

Solid Oxide Cells (SOCs) are electrochemical energy conversion devices which offer a high operating efficiency for electricity and hydrogen production in their fuel cell (SOFC) or electrolysis (SOEC) operation mode, respectively [1-3]. Nickel-yttria stabilized zirconia (NiYSZ) cermets are a commonly used SOC fuel electrode material with relatively low cost and good performance. The electrochemistry of hydrogen oxidation, taking place at the active triple phase boundary (aTPB) of $\mathrm{Ni}$, YSZ and pores, has been widely studied and is fairly well understood [4,5]. However, a wide range of experimental evidence has proven that $\mathrm{Ni}$ coarsening can accelerate electrochemical performance degradation, by damaging the cermet microstructure and reducing the active triple phase boundary length [6-8]. The investigation of $\mathrm{Ni}$ coarsening is also driven by the increasing interest in nanostructured infiltrated electrodes [9-12], whose initial performance before Ni dewetting makes this technology very promising for intermediate and low temperature operation [13-15]. However, due to the large dimensional disparity between nickel nanoparticles and the large YSZ particles of the scaffold, the dewetting mechanism itself remains challenging to investigate.

Solid-state dewetting describes the transformation of a thin film into an energetically favored set of droplets or particles at temperatures well below the melting point $[16,17]$. The driving force for dewetting is the minimization of the total energy of the free surfaces of the film and substrate as well as of the film-substrate interface [17-21]. The partially dewetted Ni film is itself a workable fuel electrode for SOCs as it provides long TPB lines if the structure is fine enough. Meanwhile, the two-dimensional morphology and connectivity of the nickel and pore phases as well as the TPB lines can be directly observed and characterized. Since the underlying mechanisms leading to dewetting of thin films are the same ones that cause 3D microstructural evolution in thick porous Ni-YSZ electrodes, the new information and understanding achieved by studying experimentally observed 2D phenomena can lead to better insight into the 3D microstructural degradation of Ni-YSZ cermets. However, so far few studies have focused on nickel film dewetting [18], with limited work on the interplay between film evolution and electrochemical degradation [22].

In this paper a 2D Ni-YSZ electrode, consisting of a $40 \mathrm{~nm}$ Ni film sputtered on a YSZ substrate, was designed to study the in-situ electrode degradation affected by Ni dewetting and depercolation, without any influence from other geometric factors. This dimensional reduction significantly simplifies the experimental setup for an in-situ environmental observation of nickel behavior under high temperature and controlled gas atmosphere at different resolutions [16,23-26], allowing for more robust and representative analysis compared to interrupted annealing $[21,27,28]$. The investigation integrates a wide range of techniques, including in-situ 
environmental scanning electron microscopy (E-SEM), electrochemical impedance spectroscopy (EIS), focused ion beam-scanning electron microscopy (FIB-SEM) and atomic force microscopy (AFM). These experimental techniques are complemented by simulations of the Ni film evolution, electrochemical models and advanced tools for image analysis. For the first time, a thorough investigation is performed to quantify the main mechanisms that drive morphological changes of $\mathrm{Ni}$ thin films and impact their electrochemical performance, highlighting the capability of predicting the effect of $\mathrm{Ni}$ evolution on the SOC fuel electrode degradation.

\section{Methods}

\subsection{Preparation of 2D Ni-YSZ symmetrical cells}

Dense pellets of 8 YSZ electrolyte (Nexceris, USA, $\varnothing=2 \mathrm{~cm}, 250-300 \mu \mathrm{m}$ thickness) were used as substrates. Pellet pre-treatment involved ultrasonic cleaning in acetone and ethanol and then annealing at $900{ }^{\circ} \mathrm{C}$ for 2 hours. The surface roughness of $\mathrm{YSZ}$ substrates was measured by AFM (Atomic Force Microscope, Bruker Innova). Following this, nickel films were deposited on both sides of the 8YSZ substrates by magnetron sputtering (Ar pressure: $2.10^{-3}$

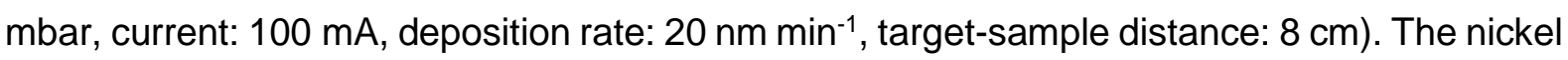
thin film covered a surface area of $2 \mathrm{~cm}^{2}$ and had a thickness of $40 \mathrm{~nm}( \pm 1 \mathrm{~nm})$.

\subsection{Real-time observation of film top morphology}

The in-situ dewetting progress was observed using a Field Emission Gun (FEG) based FEI Quanta 200 E-SEM apparatus. The test atmosphere used was humidified (3\%) forming gas (a mixture of $5 \mathrm{vol} \% \mathrm{H}_{2}$ and $95 \mathrm{vol} \% \mathrm{~N}_{2}$ ) at $170 \mathrm{~Pa}$ chamber pressure. A dedicated in-situ heating stage accurately controlled sample temperature below $600^{\circ} \mathrm{C}$ through a thermocouple in direct contact with the sample [29]. Images with different magnifications were recorded throughout each experiment. The high magnification images $\left(x 10,000,12.4 \mathrm{~nm} \mathrm{pixel}{ }^{-1}\right)$ were used to study local details of the thin layer and to determine the contact and dihedral angles, whereas low magnification images ( $\left.x 5000,24.8 \mathrm{~nm} \mathrm{pixel}^{-1}\right)$ were used for statistical analysis on a larger field of view.

\subsection{Simulation of microstructure evolution}

Both surface diffusion and fast diffusion models were used to simulate the microstructural evolution of nickel films. A simplified sketch of the two models is reported in Figure S1. The surface diffusion model is a hybrid Cellular Automata-Monte Carlo (CA-MC) model, for which the details can be found in Wang and Atkinson [30]. The surface diffusion in CA-MC is implemented by allowing each surface matter voxel a chance to move away to its surrounding 
area. The probability for the matter voxel to re-attach to a vacant voxel in its surrounding area is proportional to the sum of the energy of the matter voxel and that of the vacant voxel which can potentially be eliminated by the attachment of the matter voxel $[30,31]$. Thus, in the surface diffusion model, mass transport takes place step-by-step along the Ni surface.

The fast diffusion model uses a Cellular Automata (CA) approach. In this model, diffusion is assumed to be fast while the detachment/attachment of $\mathrm{Ni}$ atoms is the rate controlling step. In other words, this model is suitable for the processes in which energetics plays a dominant role while transport kinetics only plays a marginal role. Therefore, the kinetics of different matter transport mechanisms are not needed. The algorithm used in the fast diffusion model is similar to that used in the evaporation-condensation model by Wang [31]. Each surface matter voxel is given a chance to become a vacant voxel (in a practical sense this means that surface matter moves away from its current position). The probability of this matter voxel detachment (or erosion) is proportional to its relative free energy. In parallel, each surface vacant voxel is given a chance to be eliminated by attachment of a matter voxel. The probability of this vacant voxel elimination is proportional to the relative free energy of the vacant voxel. However, unlike the evaporation-condensation model, which allows matter to be transported between disconnected particles, in the fast diffusion model the transport between disconnected particles is prohibited.

Since the grain growth of the nickel film was observed to be significant, the simulation also takes the grain growth into account in both the surface diffusion and fast diffusion models. XRD of the as-deposited nickel film determined that the initial state of the nickel film was nearly amorphous (Figure S8). Significant grain growth was observed in the nickel film after ageing (Figure S5). The grain growth is simulated using a CA grain boundary migration model which gives each boundary voxel, located between $\mathrm{Ni}$ grains of different crystal orientations, the chance of changing its state from its initial grain to the neighboring one, as described in detail by Wang [31] and schematically depicted in Figure S1c. Therefore, the simulation consists of not only the matter transport (surface diffusion or fast diffusion) steps but also grain boundary migration steps. To synchronize the grain growth model with the matter transport model in the simulation, model calibrations were carried out to determine the real-time length for each simulated time step in different models (refer to Wang and Atkinson [30] for details of the methodology). For the specific conditions reported in this paper, it was estimated that six surface diffusion steps roughly correspond to one grain growth step in the surface diffusion model, whereas, for the fast diffusion, one matter transport step roughly corresponds one step of grain growth. All simulations were based on a Ni-YSZ wetting angle of $121^{\circ}$, as determined from FIB cross-section images (Figure S6) and consistent with the value of $126^{\circ}$ reported by 
Davis et al. [32], and a dihedral angle between neighbor Ni grains of $129^{\circ}$ (Figure S5), as calculated from the ratio of the grain boundary energy to surface energy of nickel (reported to be 0.37 by Kovalenko et al. [33]). Notably, these values are representative of open-circuit operation as the wetting angle can vary under polarization [22,34].

\subsection{Quantitative image analysis}

The E-SEM images were segmented using the open-source Trainable Weka Segmentation (TWS) tool, which is a plugin available as part of the Fiji distribution of ImageJ [35]. The TPB densities were calculated from the segmented data using an in-house code which treated the edges of the square pixels as the interface between the nickel and YSZ. Special care was given to the evaluation of the aTPB density, which is the TPB belonging to Ni clusters connected to the Pt mesh current collector used for the impedance measurements. Since the opening of the Pt mesh current collector (c. $300 \mu \mathrm{m} \times 300 \mu \mathrm{m}$ ) was significantly larger than the area imaged by E-SEM, the Ni percolation and aTPB calculated from the imaged area had to be scaled up to the opening area of the Pt mesh, which is representative of the entire electrode area. Two different approaches were used: a wire-based model and a lattice-based model.

In the wire-based model, a "wire" location was assigned across the images. Due to the uncertainty about the quality of the contact between the current collector and the nickel layer, a two-part sensitivity analysis was performed to investigate the degree of lateral percolation in the nickel phase, so that the aTPB density could also be approximated. Percolation was assessed by placing an initial "wire" column, representing the contact from a section of the current collector mesh, and then counting only those TPBs which belong to the Ni clusters with a percolating path to the wire. The first part of the sensitivity study involved placing the wire within a range of equally spaced horizontal locations and the second part varied the width of the wire column as illustrated in Figure 1. The illustration video can be found in supplementary video 1 . While varying the wire location is useful to assess the sensitivity to the random placement of the Pt mesh current collector, varying the wire width allows for the assessment of the sensitivity to the quality of the contact between the Pt mesh and the nickel layer. For the images investigated in this study, the sensitivity to both wire location and wire width were generally low. The aTPB density calculation based on this wire-based model can be found in the Supplementary Material.

The second approach used to scale up the aTPB density $\rho_{\text {aTPB }}$ from the imaged area to the electrode area, hereafter referred as the lattice-based model, combined random lattice simulations with the scaling laws of percolation theory in finite domains [22]. An in-house $\mathrm{C}++$ 
code was developed to randomly fill in square lattices, with side length $\tilde{d}$, with black pixels according to the desired coverage fraction $\tilde{\phi}$ (see Figure S2a). In these simulations, the black pixels represented the Ni phase while the white pixels represented the uncovered YSZ phase. The fraction $\tilde{\gamma}$ of black pixels connected to the lattice boundaries and the mean cluster area $\tilde{a}$ of the black phase were evaluated over 1000 random realizations for different values of coverage fraction $\tilde{\phi}$ and side length $\tilde{d}$, as reported in Figure S2b,c.

The equivalence between random lattices and imaged areas was performed as follows. Given a segmented image with side length $d$ obtained from E-SEM, the Ni coverage fraction $\phi$, the mean $\mathrm{Ni}$ cluster area $a$ and the $\mathrm{Ni}$ percolation fraction $\gamma$ with external boundaries were evaluated by image analysis. The values of $\phi$ and $a / d^{2}$ of the segmented image were used to find the side length $\tilde{d}_{1}$ of the equivalent random lattice having $\tilde{\phi}_{1}=\phi$ and $\left(\tilde{a} / \tilde{d}^{2}\right)_{1}=\left(a / d^{2}\right)$ according to Figure S2c. This allows for the evaluation of the percolation fraction $\tilde{\gamma}_{1}$ of such an equivalent lattice according to Figure $\mathrm{S} 2 \mathrm{~b}$. Then, the ratio $\delta=d_{\mathrm{m}} / d$ between the side length of the Pt mesh opening $\left(d_{\mathrm{m}}=300 \mu \mathrm{m}\right)$ and the side length of the E-SEM image $(d)$ was used to scale up the equivalent random lattice to the side length $\tilde{d}_{2}=\delta \cdot \tilde{d}_{1}$, for which the percolation fraction $\tilde{\gamma}_{2}$ was obtained by using Figure S2b for $\tilde{\phi}_{2}=\phi$. Finally, the active TPB density referred to the entire electrode area was evaluated as:

$\rho_{\text {aTPB }}=\gamma \frac{L_{T P B}}{A_{\text {image }}} \cdot \frac{\widetilde{\gamma}_{2}}{\widetilde{\gamma}_{1}}$

that is, by scaling up the percolating TPB density per unit of imaged area $\left(\gamma L_{\mathrm{TPB}} / A_{\text {image }}\right.$, where $L_{\text {TPB }}$ and $A_{\text {image }}$ are the total TPB length and the area of the imaged region, respectively) for the ratio of $\mathrm{Ni}$ percolation fractions in the equivalent random lattices $\left(\tilde{\gamma}_{2} / \tilde{\gamma}_{1}\right)$. Notably, this lattice-based model allows for the extrapolation of the active TPB density evaluated by image analysis up to the size of the Pt mesh according to the scaling laws of percolation in finite lattices.

\subsection{Electrochemical Impedance Spectroscopy}

The selected 2D Ni-YSZ symmetrical cells were tested at $600^{\circ} \mathrm{C}$ in humidified (3\%) diluted hydrogen (a mixture of $5 \mathrm{vol} \% \mathrm{H}_{2}$ and $95 \mathrm{vol} \% \mathrm{~N}_{2}$ ) at ambient pressure and open-circuit conditions. Initially, the temperature was increased by $30^{\circ} \mathrm{C} \mathrm{min}{ }^{-1}$ till it reached $500{ }^{\circ} \mathrm{C}$ and then it was increased by $10^{\circ} \mathrm{C} \mathrm{min}{ }^{-1}$ until it reached $600^{\circ} \mathrm{C}$. A $20 \mathrm{mV} \mathrm{AC}$ amplitude signal was applied in a two-electrode measurement setup, over the frequency range $10^{6} \mathrm{~Hz}-1 \mathrm{~Hz}$, which required $4 \mathrm{~min}$ for each measurement. Pt meshes were used as current collectors, where the mesh wire diameter was $60 \mu \mathrm{m}$ and the gaps between the wires were $d_{\mathrm{m}}=300 \mu \mathrm{m}$. The measurement data were fitted to an equivalent electrical circuit, reported as an inset in Figure 
7a, by using ZView3.5 (Scribner Associates Incorporated) to extract the ohmic resistance $\left(R_{1}\right)$ and the polarization resistance $\left(R_{2}\right)$ referred per unit of total electrode area (i.e., $\Omega \cdot \mathrm{cm}^{2}$ ).

Ni dewetting causes a loss in lateral percolation, so that ionic current does not flow underneath the non-percolating inactive area of the electrode. This causes an increase in ohmic resistance, $R_{1}(t)[36,37]$. On the other hand, the polarization resistance can be related to the aTPB density evolution. According to the literature, the polarization resistance $R_{2}(t)$ is inversely proportional to the TPB length $[5,38,39]$. The time-dependence of the polarization resistance $R_{2}(t)$ was used to estimate the temporal evolution of the connected TPB length per unit of electrode area $\rho_{\text {aTPB }}(t)$ :

$\rho_{a T P B}(t)=\frac{R_{c t}}{R_{2}(t)}$

where $R_{\mathrm{ct}}$ is the charge transfer resistance per unit of TPB length (i.e., $\Omega \cdot \mathrm{m}$ ). As an initial guess for the fitting of $R_{\mathrm{ct}}$, the correlations provided by de Boer [40] and Bieberle et al. [41] as a function of the operating temperature and partial pressures were used. Such an active TPB density per unit of electrode area, estimated from electrochemical impedance spectroscopy, can be compared to the $\rho_{\text {aTPB }}$ evaluated by image analysis as described in the previous section.

\section{Results and Discussion}

\subsection{Top morphology evolution}

The local morphological evolution of the $40 \mathrm{~nm}$-thick nickel layer on YSZ substrate was scrutinized at high magnification (x10,000), as shown in Figure 2, and the full video can be found in supplementary videos 2 and 3 . The nickel thin film transformation progress was recorded at two different temperatures, $560{ }^{\circ} \mathrm{C}$ and $600^{\circ} \mathrm{C}$.

According to AFM, the grain boundary depth of the $Y S Z$ substrate ranged between $30 \mathrm{~nm}$ and $50 \mathrm{~nm}$ (Figure S3). Thus, the morphology of the $40 \mathrm{~nm}$-thick Ni film in the initial stage reflected the surface features of the substrate, appearing partially separated at the YSZ grain boundaries, as shown in Figure 2 a $(t=0 \mathrm{~min})$. Initially, the nickel film was very likely in an amorphous state due to the room temperature deposition, as evidenced by the bright contrast of the grains [16]. When the temperature was raised above $450{ }^{\circ} \mathrm{C}$, the self-diffusion of $\mathrm{Ni}$ atoms was activated, causing the crystallization of the nickel layer, as reported in supplementary video 4 . Crystallization was accompanied by volume shrinkage, which led to a tensile stress in the film [42] concentrated at the most concave surface locations at the YSZ grain boundaries, which became the preferential regions for cracking of the coherent $\mathrm{Ni}$ film (Figure 2a). 
According to Figure 2, the pre-existing cracks and tensile stress of the Ni film along YSZ grain boundaries affected the initial evolution of dewetting. Figure $2 \mathrm{~b}$ clearly shows that the Ni film retracted from the YSZ boundaries. This stage involved the generation of pores along YSZ grain boundaries without any loss in $\mathrm{Ni}$ connectivity, with formation of TPBs and a corresponding increase in aTPB length. Notably, nucleation and growth of additional pores on the flat and coherent film area took place at a much later stage (Figure 2c).

As dewetting proceeded, some nickel particles gradually became isolated from the large clusters. As a result, the overall connectivity of the film decreased with time. Once small $\mathrm{Ni}$ particles became isolated, their size and shape became very stable over the whole period of observation, indicating that no significant mass transport took place among disconnected $\mathrm{Ni}$ clusters. In contrast, the microstructure of the large clusters continued to evolve, resulting in rounder and smoother TPBs at the later stages of the experiment (Figure 2d). No chemical modifications were detected upon film dewetting from XRD analysis (Figure S8).

\subsection{General behavior of Ni layer dewetting}

The low magnification $(x 5,000)$ images (videos 5 and 6) were segmented and used for quantitative analyses of parameters that are characteristic of the general features of $\mathrm{Ni}$ layer dewetting on a larger field of view, as reported in Figure 3.

Figure 3a,b shows an initial increase in total triple phase boundary (TPB) density, which was associated to the initial pore generation and the significant reduction in nickel coverage, as previously described in Figure 2b,c. At both $560{ }^{\circ} \mathrm{C}$ and $600{ }^{\circ} \mathrm{C}$, the thin film showed a significant high de-percolation rate when the nickel coverage approached 0.63 , as highlighted by the sharp decrease in percolation ratio in Figure 3a,b. Such a coverage ratio of 0.63 identifies the transition between the initial dewetting stage and the following de-percolation stage. During the de-percolation stage, isolated nickel islands were formed and the gradual film retraction led to a steady reduction in Ni-YSZ surface coverage ratio, as shown in Figure 3a,b. Finally, after $110 \mathrm{~min}$ and $25 \mathrm{~min}$ for $560^{\circ} \mathrm{C}$ and $600{ }^{\circ} \mathrm{C}$, respectively, the total TPB density from both experiments reached a relatively stable level around $5.5 \mu \mathrm{m}^{-1}$, independent of the operating temperature. The coverage and percolation ratios levelled off as well. The final nickel coverage ratio stabilized at about 0.49 for both temperatures, indicating that nickel particles reached a stable state characterized by a particle thickness of c. $80 \mathrm{~nm}$.

Figure $3 c$ shows that all the relevant microstructural properties are successfully rescaled with sufficient precision by using a single time scaling factor $r_{\tau}$, equal to the ratio of times corresponding to a coverage fraction of 0.63 for different temperatures. This indicates that 
dewetting and retraction phenomena proceed according to the same dominant mechanisms over the range $560-600^{\circ} \mathrm{C}[16]$. The calculated time scaling factor used in Figure $3 \mathrm{c}$ is equal to $r_{\tau}=3.91$, which means that the dewetting rate becomes roughly four times faster from 560 ${ }^{\circ} \mathrm{C}$ to $600^{\circ} \mathrm{C}$. Assuming thermal activation of the kinetics of Ni dewetting phenomena, for each absolute temperature $T$ the characteristic time of dewetting $\tau_{T}$ can be expressed according to

an Arrhenius-type law $\tau_{T}=c \cdot \exp \left(\frac{E_{a c t}}{\kappa T}\right)$, where $\kappa$ is the Boltzmann constant, $E_{\text {act }}$ is the activation energy of the characteristic rate of dewetting and $c$ is a dimensional constant [16]. Therefore, since the time scaling factor $r_{\tau}$ defined above equals the ratio of characteristic times at different temperatures (i.e., $r_{\tau}=\tau_{560^{\circ} \mathrm{C}} / \tau_{600^{\circ} \mathrm{C}}$ ), an approximate estimation of the activation energy $E_{\text {act }}$ is obtained [16], resulting equal to $2.1 \mathrm{eV}$ for a $40 \mathrm{~nm} \mathrm{Ni}$ film on YSZ. As shown by Niekiel et al. [16], such an activation energy describes, in a lamped fashion, the energy barrier required to activate the kinetics of dewetting of a thin film, providing semiquantitative indications on the ruling dewetting mechanisms as further elaborated in section 3.4 .

\subsection{Active TPB density from image analysis}

Two models, namely the wire model and the lattice model, were used for estimating the aTPB density in low magnification images by scaling up the percolation properties to the entire electrode area, thus enabling comparison with EIS measurements, discussed in the last section.

The evolution of the aTPB density with time showed the same trends in both models, as reported by the green and light blue curves in Figure 4a,b. The early stage was characterized by an increase in aTPB density with time, corresponding to the dewetting progress from a dense nickel thin film to a highly porous percolating network. In this initial stage, characterized by pore nucleation around the film defects (Figure $2 b$ ), the Ni phase is almost entirely percolating, so that the aTPB per unit of electrode area basically coincides with the total TPB density (Figure 4a,b).

As dewetting proceeded, an intermediate stage began, characterized by a sharp reduction of percolation of $\mathrm{Ni}$ clusters (blue lines in Figure $3 a, b$ ). While the formation of total TPBs continued to increase due to pore generation (dark blue line in Figure 4a,b), the loss in $\mathrm{Ni}$ percolation slowed down the increase in aTPB, which reached a peak. Both models consistently identify the temporary maximum in aTPB, which corresponded to a Ni coverage ratio slightly larger than the turning point of 0.63 previously identified, as shown in Figure 4c. Irrespective of temperature, the competition between $\mathrm{Ni}$ de-percolation and pore nucleation gives rise to a maximum in aTPB density just before the sharp loss in Ni connectivity. 
After reaching the peak, the aTPB density decreased quickly with time due to the loss in $\mathrm{Ni}$ percolation (Figure 4c), finally reaching a stable aTPB density value during the final retraction stage. The final minimum aTPB values should not be regarded as representative of the dewetting process itself as they were controlled by the active nickel particles in direct contact with the current collector.

\subsection{Simulation of Ni microstructure evolution}

In order to obtain a mechanistic insight into the mechanisms that govern Ni dewetting, cellular automata simulations were performed and compared with the image analysis of experimental E-SEM images. Since grain boundary and interface diffusion can play a crucial role in solidstate dewetting [18,24,43] in addition to surface self-diffusion [17], two models were considered: a surface diffusion model (Figure S1a), in which Ni transport took place along the Ni surface, and a fast diffusion model (Figure S1b), in which transport kinetics was neglected and a high-energy $\mathrm{Ni}$ site could fill in a low-energy vacant site in a single step. In both models, no transport between isolated Ni clusters was allowed.

As previously discussed in Figure 2, dewetting started from the pre-existing cracks of the $\mathrm{Ni}$ film. In order to mimic the starting configuration of the film, crack-like defects were introduced in the initial microstructure used as a basis for simulation (Figure $5 \mathrm{a}, \mathrm{c}$ ). The microstructural evolution simulated by the fast diffusion model, shown in Figure $5 \mathrm{c}$, d and in video 8 , is fairly close to what was observed in experiments. According to this model, pores mainly evolve from the pre-existing cracks, with a limited additional pore nucleation within the bulk of the dense $\mathrm{Ni}$ regions. In addition, the resulting Ni grains show sharp facets. All these features are in agreement with experimental observations, as clearly noticeable by comparing Figure $5 d$ with Figure 2c, although some minor discrepancies exist, especially regarding the jerky dynamics of pore progression. On the other hand, the surface diffusion model (Figure 5a,b and video 7) fails to predict the shrinkage of $\mathrm{Ni}$ clusters, the lack of small isolated $\mathrm{Ni}$ grains and the preferential expansion of pores from pre-existing defects. In fact, there are several morphological differences between the microstructure obtained by surface diffusion simulation (Figure $5 b$ ) and the experimental one (Figure 2c), such as the rounder shape and the smaller size of $\mathrm{Ni}$ clusters as resulting from the surface diffusion simulation.

A quantitative comparison between model simulations and experimental data is shown in Figure 6, which reports some key microstructural properties at the Ni percolation threshold, correctly identified by both models and experiments at about $60 \%$ nickel coverage ratio. The fast diffusion model predicts pore and Ni sizes as well as a TPB density value in good agreement with those measured in E-SEM images. On the contrary, the surface diffusion 
model underestimates both the pore size and Ni size by roughly a factor three and significantly overestimates the TPB density.

Therefore, both visual (Figure $5 c, d$ ) and quantitative (Figure 6) analyses indicate that the surface diffusion mechanism is inadequate to represent the dynamics of $\mathrm{Ni}$ dewetting, in agreement with Amram et al. [18]. Furthermore, based on the experimental observation that small isolated nickel particles did not change size once detached from large clusters (videos 2, 3, 5 and 6), we can conclude that nickel transport along the YSZ free surface was very limited, if not impossible. This observation rules out the possibility of an evaporationcondensation mechanism [31], as also confirmed by the stability of Ni nanoparticles after annealing at $800^{\circ} \mathrm{C}$ (Figure S7).

The good predictions given by the fast diffusion model suggest that there may exist a fast transport mechanism, such as the fast interfacial diffusion evidenced by Amram et al. [18]. Regardless of the specific transport mechanism, simulation results highlight that the dewetting rate is mainly controlled by the energetics of pore nucleation rather than by $\mathrm{Ni}$ transport. In other words, the activation energy of pore nucleation is larger than the activation energy of $\mathrm{Ni}$ diffusion, so that the formation of new pores, which allows dewetting to proceed, is ruled by the energy barrier of pore nucleation rather than by the rate of mass transport. The hypothesis of pore nucleation being the main energy barrier of $\mathrm{Ni}$ dewetting is also supported by the estimated activation energy in Figure $3 \mathrm{c}$, equal to $2.1 \mathrm{eV}$, which is much larger than the typical activation energy of $\mathrm{Ni}$ surface diffusion, equal to $0.7-1.0 \mathrm{eV}$ [44].

\subsection{Match of microstructure and electrochemistry}

The link between microstructural evolution and electrochemical response of the $\mathrm{Ni}$ film was assessed by comparing image analysis, simulations and impedance spectroscopy data, which is reported in Figure $7 \mathrm{a}$ for $600{ }^{\circ} \mathrm{C}$ and $1 \mathrm{~atm}$. Only one temperature was sufficient for EIS investigation because the microstructural evolution at different temperatures can be rescaled with a single scaling factor (Figure $3 c$ and Figure 4c). Notably, E-SEM imaging and EIS data refer to two nominally equal but distinct samples, thus some variations are expected due to variance in sample fabrication and differences in operating conditions. In addition, in EIS measurements a Pt mesh current collector was used, whose opening (c. $300 \mu \mathrm{m} \times 300 \mu \mathrm{m}$ ) was significantly larger than the area imaged by E-SEM.

Figure 7a shows that initially the electrode gave high values of ohmic resistance $\left(R_{1}\right)$ and polarization resistance $\left(R_{2}\right)$, which both decreased within the first 20 minutes. According to image analysis, within the first minutes the electrode corresponds to a dense $\mathrm{Ni}$ layer with sparsely dispersed defects/pores (Figure 2a,b) where the electrochemical reaction occurs and 
ionic current flows perpendicularly underneath, resulting in large values of ohmic and polarization resistances. As soon as dewetting began, more pores and TPBs were generated (Figure 2c) until they could be considered uniformly distributed on the entire planar area, giving a minimum in ohmic resistance, as shown in Figure 7a. Any subsequent increase in ohmic resistance can be attributed to the loss in long-range Ni percolation from the mesh current collector, leading to an increasing fraction of electrode inactive area [45]. This matches well with the abrupt decrease in Ni percolation ratio identified in Figure 3b for a Ni coverage ratio lower than 0.63 . Therefore, the whole temporal behavior of the ohmic resistance can be interpreted on the basis of the appearance of a uniform distribution of pores and aTPBs followed by the loss in long-range Ni percolation, in good agreement with the microstructural evolution reported in Figure 2 and Figure 3b.

The polarization resistance $R_{2}$ enables for estimation of the aTPB density (Figure 7b) considering that aTPB density and $R_{2}$ are inversely proportional $[5,38,39]$, as reported in Equation (2). Figure $7 \mathrm{a}$ shows that the minimum in polarization resistance took place before the minimum in ohmic resistance: this can be satisfactorily explained by the maximum in aTPB density which appears before the loss of $\mathrm{Ni}$ percolation for coverage ratios lower than 0.63 (Figure 4c). Then, as Ni de-percolation started, the polarization resistance increased sharply, matching the abrupt decrease in aTPB density for a coverage fraction smaller than 0.63. Thus, also the temporal evolution of the polarization resistance can be interpreted on the basis of the changes of the Ni film microstructure.

Figure $7 \mathrm{~b}$ compares aTPB density values independently estimated from EIS, E-SEM images and fast diffusion simulation. Since the Ni-YSZ wetting angle is larger than $90^{\circ}$, the actual TPB is hidden underneath nickel particles. Simulation results show that the actual aTPB (3D) is roughly twice as large as the projected aTPB (2D). Nevertheless, the 2D aTPB can correctly identify the main phenomena characterizing $\mathrm{Ni}$ dewetting, such as the times at which the maximum in aTPB density and the drop in Ni percolation occur, in good agreement with experimental E-SEM observations.

Regarding the aTPB estimated from EIS data, a line-specific resistance of $3.63 \cdot 10^{4} \Omega \cdot \mathrm{m}$, lying between estimations of de Boer [40] and Bieberle et al. [41] correlations, enabled for the match of the aTPB peak from 3D simulation. A broader peak in aTPB was obtained from EIS analysis because EIS detects the global response of the electrode, thus it is subject to a larger statistical dispersion. Nevertheless, the aTPB density estimated via EIS followed closely the 3D aTPB values. 
In summary, results show that the electrochemical degradation of the $\mathrm{Ni}$ film can be quantitatively explained in terms of loss in Ni percolation and aTPB, thus, in terms of the microstructural evolution of the film. This demonstrates that the electrochemical degradation detected via EIS in the Ni film is entirely due to the microstructural evolution of the film itself. Such a good match also suggests that the microstructural evolution can be tracked using EIS and, vice versa, the electrochemical degradation of the Ni film electrode can be predicted by means of microstructural analysis and microstructural models.

\section{Conclusions}

This paper reported a comprehensive study of the microstructural and electrochemical evolution of $40 \mathrm{~nm}$ nickel films on YSZ substrates under humidified hydrogen at $560-600{ }^{\circ} \mathrm{C}$. E-SEM observations revealed that film dewetting originated from pre-existing film cracks above the YSZ grain boundaries. Microstructural evolution occurred only within connected $\mathrm{Ni}$ clusters, no mass transport was observed among isolated Ni particles. Additional pore nucleation in the bulk of the Ni film took place only at a late stage. The high energy barrier of pore nucleation was confirmed by cellular automata simulations, which revealed that neither surface diffusion nor evaporation-condensation mechanisms were compatible with the observed film evolution. On the contrary, the energetics of pore nucleation represents the dominant energy barrier, with an apparent activation energy of $2.1 \mathrm{eV}$.

The analysis of the active triple phase boundary density revealed that $2 \mathrm{D}$ images underestimate the real aTPB. Nevertheless, 2D image analysis showed that aTPB density initially increased and then dropped as soon as the Ni coverage ratio approached 0.63 , which identified the start of the de-percolation stage. Both the peak and the abrupt drop in aTPB density were satisfactorily correlated to the impedance response, thus univocally linking the microstructural evolution to the electrochemical degradation of 2D Ni-YSZ electrodes.

The outcomes of the study have significant implications for SOFC and SOEC technology for conditions close to open-circuit operation. From a methodological viewpoint, the quantitative link between microstructural evolution and electrochemical response enables the prediction of electrochemical degradation via in-situ microstructural observation and, vice versa, the investigation of microstructural evolution phenomena through EIS at open-circuit conditions. From a technological perspective, as pore nucleation represents the most important energy barrier of dewetting, reducing the number of nucleation points by removing defects and dust, controlling the purity and surface properties of materials or by increasing the YSZ grain size, may significantly slow down the dewetting rate. While all these points require specific individual studies, the proposed methodology provides a convenient platform to investigate 
other phenomena, such as redox cycling, poisoning and carbon deposition in simplified and controlled conditions, thus supporting material and technological research.

\section{Acknowledgements}

This project has received funding from the China Scholarship Council (CSC), European Union's Horizon 2020 research and innovation programme under the Marie Skłodowska-Curie grant agreement No 654915 and the EPSRC grant EP/M014045/1.

\section{References}

[1] N.P. Brandon, Solid oxide fuel cell lifetime and reliability: Critical challenges in fuel cells, 1st ed., Academic Press, 2017.

[2] J.T.S. Irvine, D. Neagu, M.C. Verbraeken, C. Chatzichristodoulou, C. Graves, M.B. Mogensen, Evolution of the electrochemical interface in high-temperature fuel cells and electrolysers, Nat. Energy. 1 (2016) 15014. doi:10.1038/nenergy.2015.14.

[3] N.P. Brandon, S.J. Skinner, B.C.H. Steele, Recent advances in materials for fuel cells, Annu. Rev. Mater. Res. 33 (2003) 183-213. doi:10.1146/annurev.matsci.33.022802.094122.

[4] D.G. Goodwin, H. Zhu, A.M. Colclasure, R.J. Kee, Modeling electrochemical oxidation of hydrogen in Ni-YSZ pattern anodes, J. Electrochem. Soc. 156 (2009) B1004-B1021. doi:10.1149/1.3148331.

[5] M. Vogler, A. Bieberle-hütter, L. Gauckler, J. Warnatz, W.G. Bessler, Modelling study of surface reactions, diffusion, and spillover at a Ni/YSZ patterned anode, $\mathrm{J}$. Electrochem. Soc. 156 (2009) B663-B672. doi:10.1149/1.3095477.

[6] S. Tao, J.T.S. Irvine, A redox-stable efficient anode for solid-oxide fuel cells, Nat. Mater. 2 (2003) 320-3. doi:10.1038/nmat871.

[7] B. Song, E. Ruiz-Trejo, A. Bertei, N.P. Brandon, Quantification of the degradation of NiYSZ anodes upon redox cycling, J. Power Sources. 374 (2018) 61-68. doi:10.1016/j.jpowsour.2017.11.024.

[8] G.J. Nelson, K.N. Grew, J.R. Izzo, J.J. Lombardo, W.M. Harris, A. Faes, A. HesslerWyser, J. Van Herle, S. Wang, Y.S. Chu, A. V. Virkar, W.K.S. Chiu, Three-dimensional microstructural changes in the Ni-YSZ solid oxide fuel cell anode during operation, Acta Mater. 60 (2012) 3491-3500. doi:10.1016/j.actamat.2012.02.041. 
[9] S.P. Jiang, A review of wet impregnation-An alternative method for the fabrication of high performance and nano-structured electrodes of solid oxide fuel cells, Mater. Sci. Eng. A. 418 (2006) 199-210. doi:10.1016/j.msea.2005.11.052.

[10] Z. Liu, B. Liu, D. Ding, M. Liu, F. Chen, C. Xia, Fabrication and modification of solid oxide fuel cell anodes via wet impregnation/infiltration technique, J. Power Sources. 237 (2013) 243-259. doi:10.1016/j.jpowsour.2013.03.025.

[11] R.J. Gorte, J.M. Vohs, Nanostructured anodes for solid oxide fuel cells, Curr. Opin. Colloid Interface Sci. 14 (2009) 236-244. doi:10.1016/j.cocis.2009.04.006.

[12] K. Joong Yoon, M. Biswas, H.-J. Kim, M. Park, J. Hong, H. Kim, J.-W. Son, J.-H. Lee, B.-K. Kim, H.-W. Lee, Nano-tailoring of infiltrated catalysts for high-temperature solid oxide regenerative fuel cells, Nano Energy. $36 \quad$ (2017) 9-20. doi:10.1016/j.nanoen.2017.04.024.

[13] P. Keyvanfar, V. Birss, Optimization of infiltration techniques used to construct Ni/YSZ anodes, J. Electrochem. Soc. 161 (2014) F660-F667. doi:10.1149/2.056405jes.

[14] P. Keyvanfar, A.R. Hanifi, P. Sarkar, T.H. Etsell, V.I. Birss, Enhancing the stability of infiltrated Ni/YSZ anodes, ECS Trans. $68 \quad$ (2015) 1255-1263. doi:10.1149/06801.1255ecst.

[15] A. Bertei, E. Ruiz-Trejo, K. Kareh, V. Yufit, X. Wang, F. Tariq, N.P. Brandon, The fractal nature of the three-phase boundary: A heuristic approach to the degradation of nanostructured solid oxide fuel cell anodes, Nano Energy. 38 (2017) 526-536. doi:10.1016/j.nanoen.2017.06.028.

[16] F. Niekiel, P. Schweizer, S.M. Kraschewski, B. Butz, E. Spiecker, The process of solidstate dewetting of $\mathrm{Au}$ thin films studied by in situ scanning transmission electron microscopy, Acta Mater. 90 (2015) 118-132. doi:10.1016/J.ACTAMAT.2015.01.072.

[17] C. V. Thompson, Solid-State Dewetting of Thin Films, Annu. Rev. Mater. Res. 42 (2012) 399-434. doi:10.1146/annurev-matsci-070511-155048.

[18] D. Amram, L. Klinger, N. Gazit, H. Gluska, E. Rabkin, Grain boundary grooving in thin films revisited: The role of interface diffusion, Acta Mater. 69 (2014) 386-396. doi:10.1016/J.ACTAMAT.2014.02.008.

[19] S.J. Randolph, J.D. Fowlkes, A. V Melechko, K.L. Klein, H.M. Meyer III, M.L. Simpson, 
P.D. Rack, Controlling thin film structure for the dewetting of catalyst nanoparticle arrays for subsequent carbon nanofiber growth, Nanotechnology. 18 (2007) 465304. doi:10.1088/0957-4484/18/46/465304.

[20] A. Geissler, M. He, J.-M. Benoit, P. Petit, Effect of Hydrogen Pressure on the Size of Nickel Nanoparticles Formed during Dewetting and Reduction of Thin Nickel Films, J. Phys. Chem. C. 114 (2010) 89-92. doi:10.1021/jp908427r.

[21] N.J. Simrick, J.A. Kilner, A. Atkinson, Thermal stability of silver thin films on zirconia substrates, Thin Solid Films. 520 (2012) 2855-2867. doi:10.1016/J.TSF.2011.11.048.

[22] Z. Jiao, N. Shikazono, Study on the effects of polarization on local morphological change of nickel at active three-phase-boundary using patterned nickel-film electrode in solid oxide fuel cell anode, Acta Mater. 135 (2017) 124-131. doi:10.1016/J.ACTAMAT.2017.05.051.

[23] G. Atiya, D. Chatain, V. Mikhelashvili, G. Eisenstein, W.D. Kaplan, The role of abnormal grain growth on solid-state dewetting kinetics, Acta Mater. 81 (2014) 304-314. doi:10.1016/J.ACTAMAT.2014.08.038.

[24] A. Kosinova, L. Klinger, O. Kovalenko, E. Rabkin, The role of grain boundary sliding in solid-state dewetting of thin polycrystalline films, Scr. Mater. 82 (2014) 33-36. doi:10.1016/J.SCRIPTAMAT.2014.03.015.

[25] Q. Jeangros, T.W. Hansen, J.B. Wagner, C.D. Damsgaard, R.E. Dunin-Borkowski, C. Hébert, J. Van herle, A. Hessler-Wyser, Reduction of nickel oxide particles by hydrogen studied in an environmental TEM, J. Mater. Sci. 48 (2013) 2893-2907. doi:10.1007/s10853-012-7001-2.

[26] M. Niania, R. Podor, T. Ben Britton, C. Li, S.J. Cooper, N. Svetkov, S.J. Skinner, J.A. Kilner, In situ study of strontium segregation in La0.6Sr0.4Co0.2Fe0.8O3- $\delta$ in ambient atmospheres using high-temperature environmental scanning electron microscopy, J. Mater. Chem. A. 6 (2018) 14120-14135. doi:10.1039/C8TA01341A.

[27] E. Mutoro, S. Günther, B. Luerßen, I. Valov, J. Janek, Electrode activation and degradation: Morphology changes of platinum electrodes on YSZ during electrochemical polarisation, Solid State lonics. 179 (2008) 1835-1848. doi:10.1016/J.SSI.2008.05.007.

[28] A. Utz, H. Störmer, D. Gerthsen, A. Weber, E. Ivers-Tiffée, Microstructure stability 
studies of Ni patterned anodes for SOFC, Solid State lonics. 192 (2011) 565-570. doi:10.1016/J.SSI.2010.05.004.

[29] R. Podor, D. Pailhon, J. Ravaux, H.-P. Brau, Development of an Integrated Thermocouple for the Accurate Sample Temperature Measurement During High Temperature Environmental Scanning Electron Microscopy (HT-ESEM) Experiments, Microsc. Microanal. 21 (2015) 307-312. doi:10.1017/S1431927615000252.

[30] X. Wang, A. Atkinson, Combining densification and coarsening in a Cellular AutomataMonte-Carlo simulation of sintering: Methodology and calibration, Comput. Mater. Sci. 143 (2018) 338-349. doi:10.1016/J.COMMATSCI.2017.11.023.

[31] X. Wang, Modelling and understanding materials microstructure evolution driven by interface energy, Comput. Mater. Sci. $107 \quad$ (2015) 1-7. doi:10.1016/j.commatsci.2015.04.034.

[32] R. Davis, F. Abdeljawad, J. Lillibridge, M. Haataja, Phase wettability and microstructural evolution in solid oxide fuel cell anode materials, Acta Mater. 78 (2014) 271-281. doi:10.1016/j.actamat.2014.06.037.

[33] O. Kovalenko, J.R. Greer, E. Rabkin, Solid-state dewetting of thin iron films on sapphire substrates controlled by grain boundary diffusion, Acta Mater. 61 (2013) 3148-3156. doi:10.1016/J.ACTAMAT.2013.01.062.

[34] P. Gasper, Y. Lu, S.N. Basu, S. Gopalan, U.B. Pal, Effect of anodic current density on the spreading of infiltrated nickel nanoparticles in nickel-yttria stabilized zirconia cermet anodes, J. Power Sources. 410-411 (2019) 196-203. doi:10.1016/j.jpowsour.2018.11.002.

[35] I. Arganda-Carreras, V. Kaynig, C. Rueden, K.W. Eliceiri, J. Schindelin, A. Cardona, H. Sebastian Seung, Trainable Weka Segmentation: a machine learning tool for microscopy pixel classification, Bioinformatics. 33 (2017) 2424-2426. doi:10.1093/bioinformatics/btx180.

[36] B. Song, E. Ruiz-Trejo, N.P. Brandon, Enhanced mechanical stability of Ni-YSZ scaffold demonstrated by nanoindentation and Electrochemical Impedance Spectroscopy, J. Power Sources. 395 (2018) 205-211. doi:10.1016/j.jpowsour.2018.05.075.

[37] J.I. Gazzarri, O. Kesler, Electrochemical AC impedance model of a solid oxide fuel cell and its application to diagnosis of multiple degradation modes, J. Power Sources. 167 
(2007) 100-110. doi:10.1016/j.jpowsour.2007.02.010.

[38] A. Utz, The electrochemical oxidation of $\mathrm{H} 2$ and $\mathrm{CO}$ at patterned $\mathrm{Ni}$ anodes of SOFCs, Karlsruher Institut für Technologie (KIT), Germany, 2011.

[39] A. Utz, J. Joos, A. Weber, E. Ivers-Tiffée, Electrochemical Oxidation at SOFC Anodes: Comparison of Patterned Nickel Anodes and Nickel/8YSZ Cermet Anodes, in: ECS Trans., The Electrochemical Society, 2011: pp. 1669-1682. doi:10.1149/1.3570154.

[40] R.S.G. Baert, P.J.M. Frijters, B. Somers, C.C.M. Luijten, W. de Boer, Design and Operation of a High Pressure, High Temperature Cell for HD Diesel Spray Diagnostics: Guidelines and Results, in: 2009. doi:10.4271/2009-01-0649.

[41] A. Bieberle, L.P. Meier, L.J. Gauckler, The electrochemistry of Ni pattern anodes used as solid oxide fuel cell model electrodes, J. Electrochem. Soc. 148 (2001) A646-A656. doi:10.1149/1.1372219.

[42] H. Gao, Stress concentration at slightly undulating surfaces, J. Mech. Phys. Solids. 39 (1991) 443-458. doi:10.1016/0022-5096(91)90035-M.

[43] A. Kosinova, O. Kovalenko, L. Klinger, E. Rabkin, Mechanisms of solid-state dewetting of thin Au films in different annealing atmospheres, Acta Mater. 83 (2015) 91-101. doi:10.1016/J.ACTAMAT.2014.09.049.

[44] J.. Blakely, H. Mykura, Surface self diffusion measurements on nickel by the mass transfer method, Acta Metall. 9 (1961) 23-31. doi:10.1016/0001-6160(61)90034-7.

[45] J. Chen, A. Bertei, E. Ruiz-Trejo, A. Atkinson, N.P. Brandon, Characterization of degradation in nickel impregnated scandia-stabilize zirconia electrodes during isothermal annealing, J. Electrochem. Soc. 164 (2017) F935-F943. doi:10.1149/2.0821709jes. 


\section{FIGURES}

\section{Figure 1}
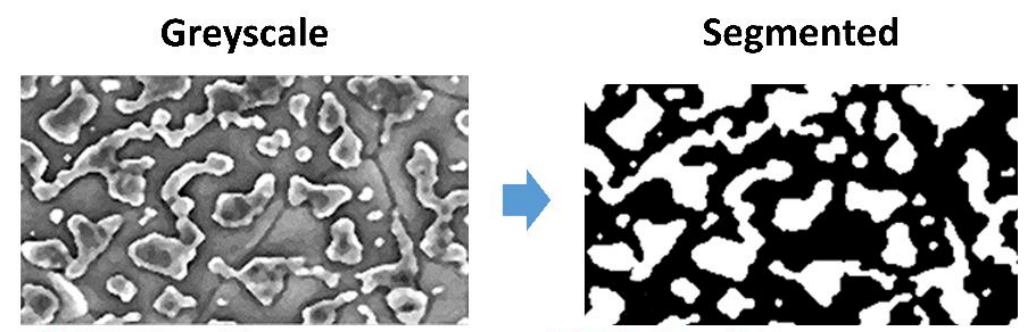

Sensitivity
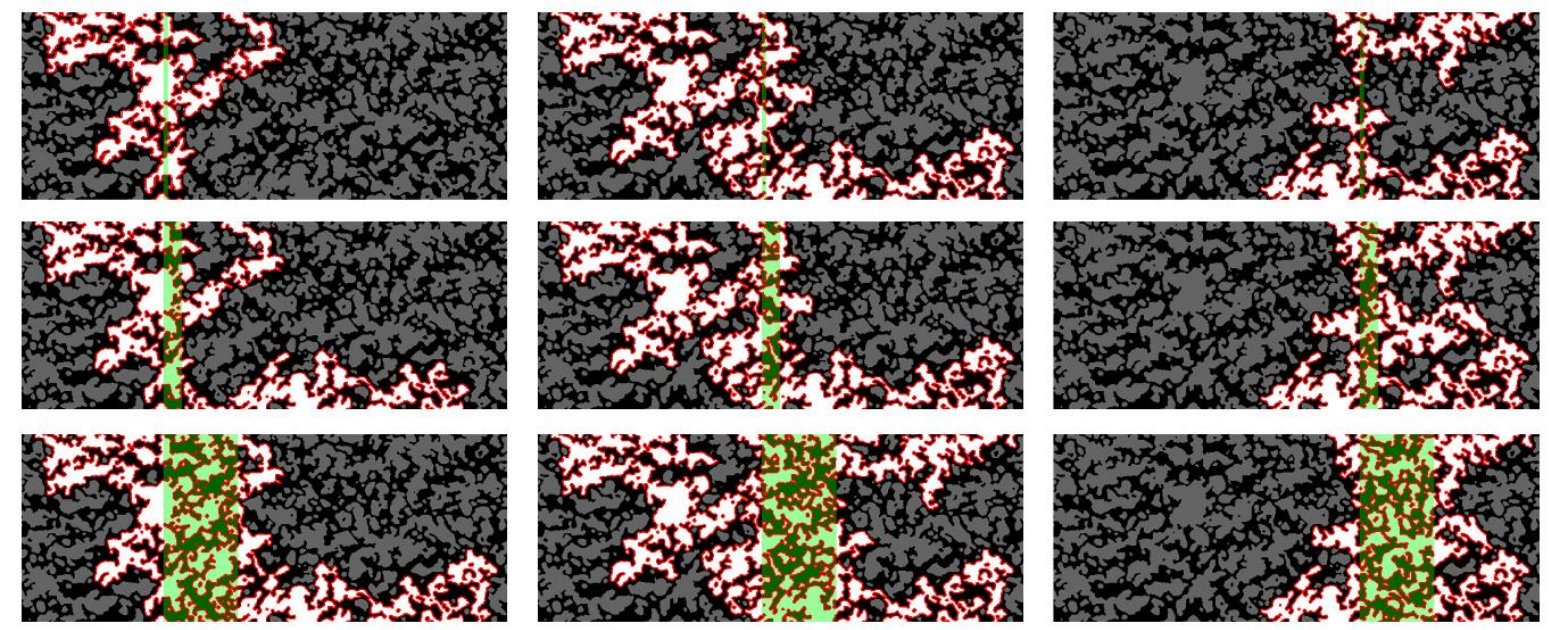

Figure 1 - The image segmentation and wire-based model used for aTPB statistics. The green line represents the wire current collector located at different regions with different widths. The white area is the percolated nickel in contact with the wire current collector and the red line surrounding the white particles represents the corresponding active triple phase boundaries. All boundaries between the white and black phases are considered aTPB. The sensitivity of the aTPB density to the location and thickness of the wire contact was investigated by varying these two parameters, as shown in the $3 \times 3$ grid. The actually imaged region was around three times larger than the regions shown in the grid. 


\section{Figure 2}

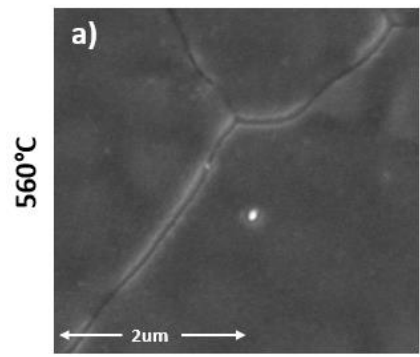

Time: 0 min

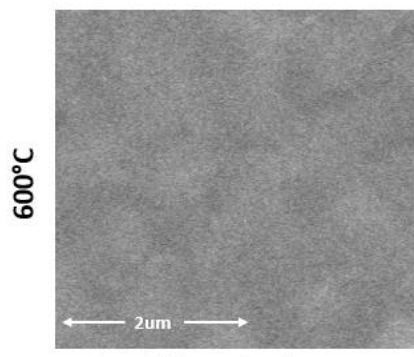

Time: 0 min

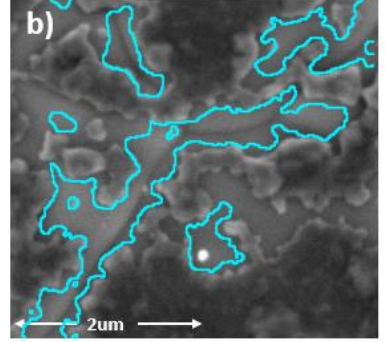

Time: $30 \mathrm{~min}-60 \mathrm{~min}$

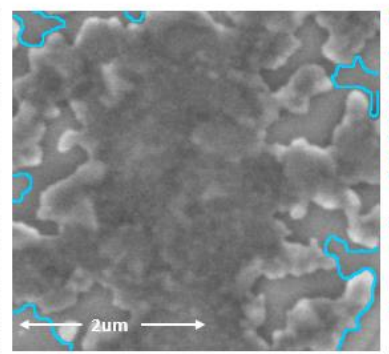

Time: 2 min - 12 min

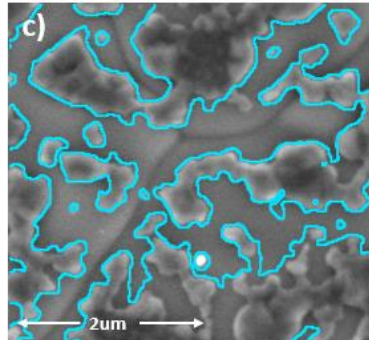

Time: $70 \mathrm{~min}-100 \mathrm{~min}$

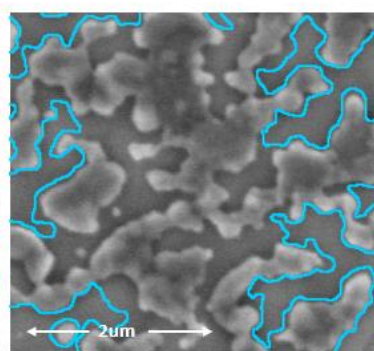

Time: $16 \min -25 \min$

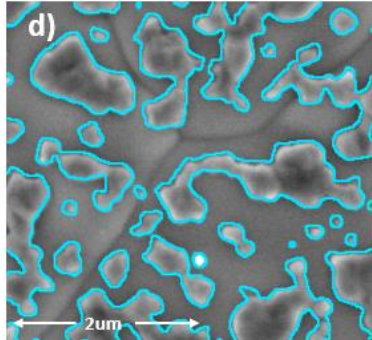

Time: $120 \mathrm{~min}$ - $137 \mathrm{~min}$

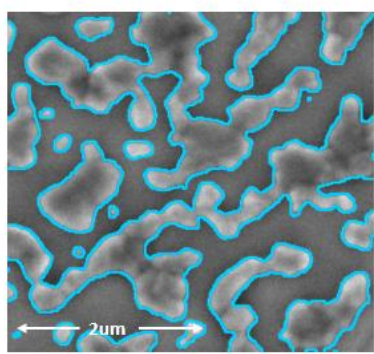

Time: $\mathbf{3 0} \mathrm{min}-\mathbf{3 5} \mathrm{min}$

Figure 2 - Top morphology evolution of $\mathrm{Ni}$ films during dewetting at two different temperatures. The experimental images refer to a $40 \mathrm{~nm}$ nickel film supported on zirconia, annealed at $560^{\circ} \mathrm{C}$ and $600^{\circ} \mathrm{C}$ in a $3 \%$ humidified $5 \% / 95 \% \mathrm{H}_{2} / \mathrm{N}_{2}$ gas mixture at $170 \mathrm{~Pa}$. The images show the evolution of $\mathrm{Ni}$ from a dense film (a), the appearance of pores and TPBs at the pre-existing defects (b), the growth of pores and reduction of Ni coverage (c) until the final state, consisting of isolated Ni clusters, is reached (d). Light blue lines represent the nickel particle boundaries at the initial time and the background SEM image is the real morphology at the end time, as indicated under each image. 


\section{Figure 3}
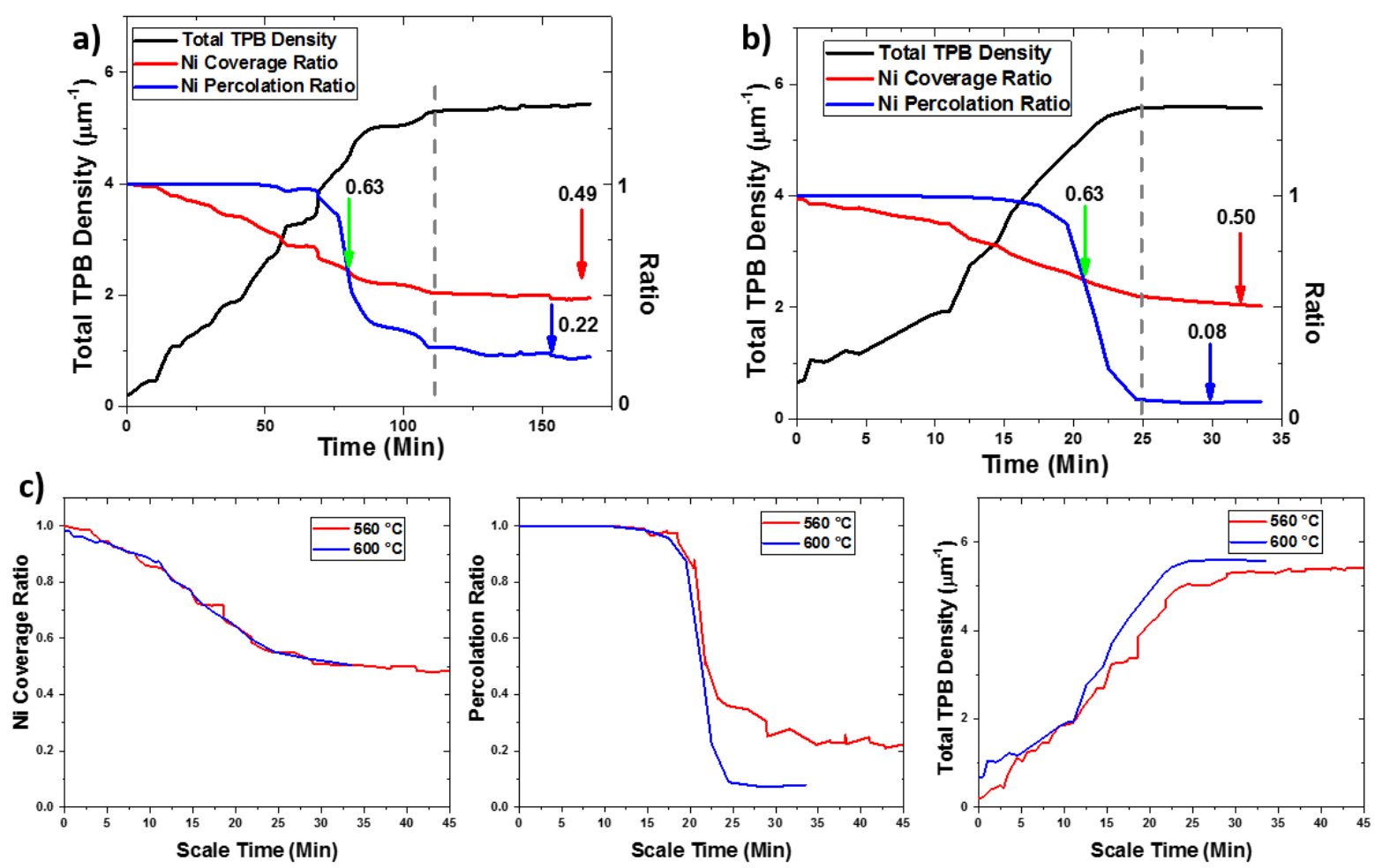

Figure 3 - TPB density, $\mathrm{Ni}$ area coverage ratio and $\mathrm{Ni}$ percolation ratio statistics evaluated in low magnification segmented images at two different temperatures. Microstructural data calculated from series of E-SEM images recorded at a) $T=560^{\circ} \mathrm{C}$ and b) $T=600^{\circ} \mathrm{C}$. c) Superposition of data at $T=$ $560^{\circ} \mathrm{C}$ (red lines) and $T=600^{\circ} \mathrm{C}$ (blue lines) after scaling the time of the data at $T=560^{\circ} \mathrm{C}$ according to the ratio of times corresponding to a coverage fraction of 0.63 . The vertical dashed lines indicate the start of the final stabilization stage. 


\section{Figure 4}
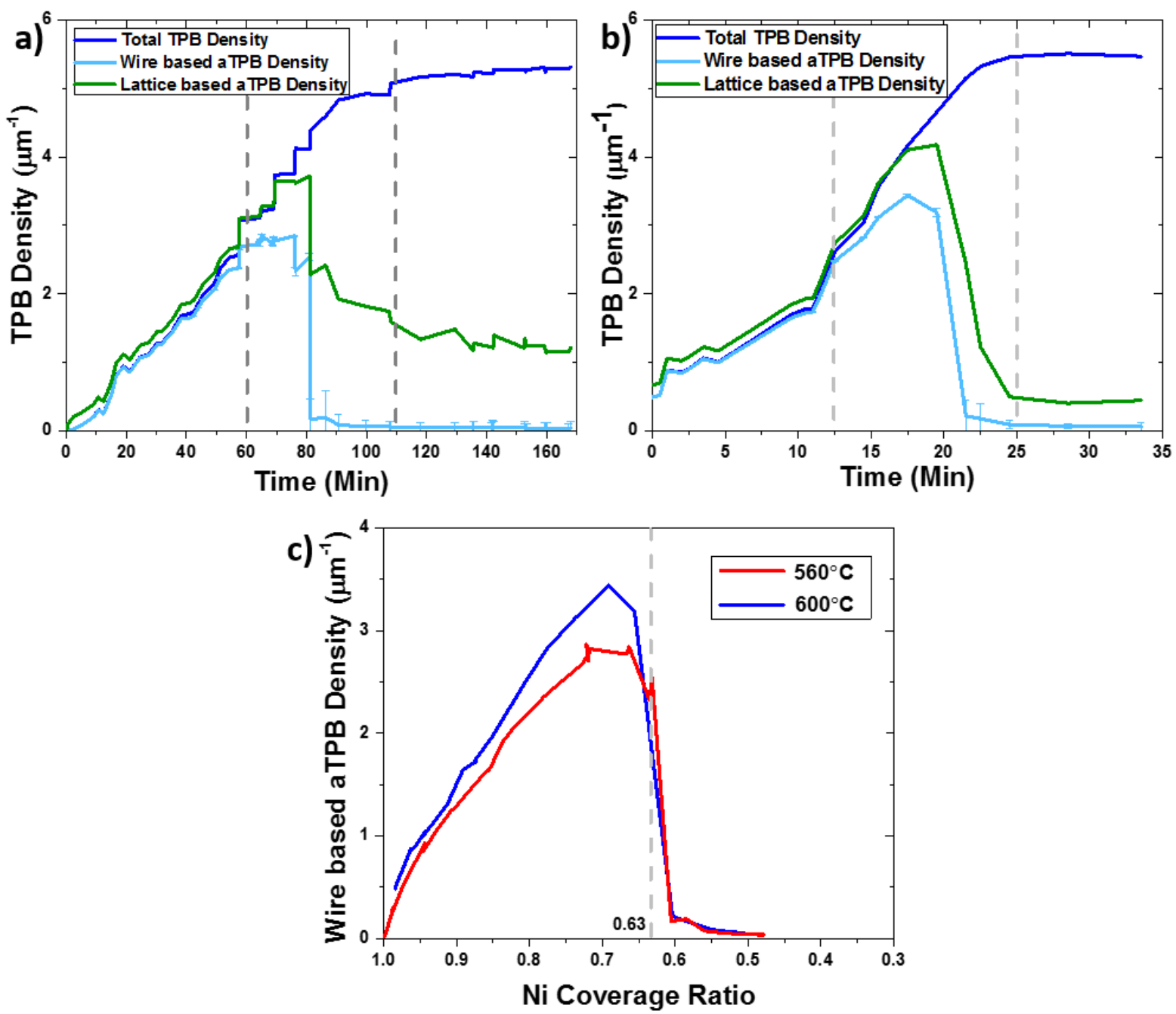

Figure 4 - Analysis of the active triple phase boundary density estimated by two models at different temperatures. The active TPB density is evaluated based on the wire model (light blue) and the lattice model (green) for the two samples recorded at a) $T=560{ }^{\circ} \mathrm{C}$ and b) $T=600{ }^{\circ} \mathrm{C}$. The dark blue line shows the total TPB density evaluated from low magnification images as already reported in Figure 3. c) aTPB from wire-based model as a function of the Ni coverage ratio (note that the $\mathrm{x}$-axis reports values in reverse order as the coverage ratio decreases with time). 
Figure 5

a)

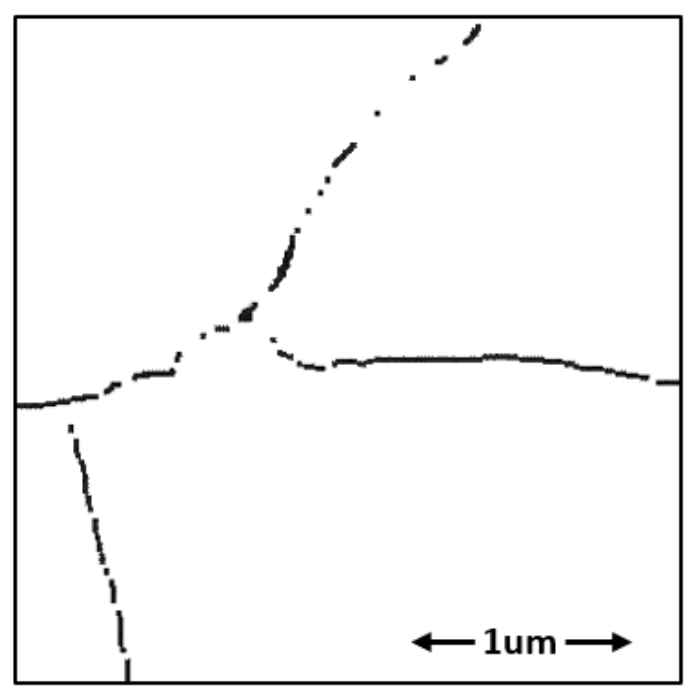

c)

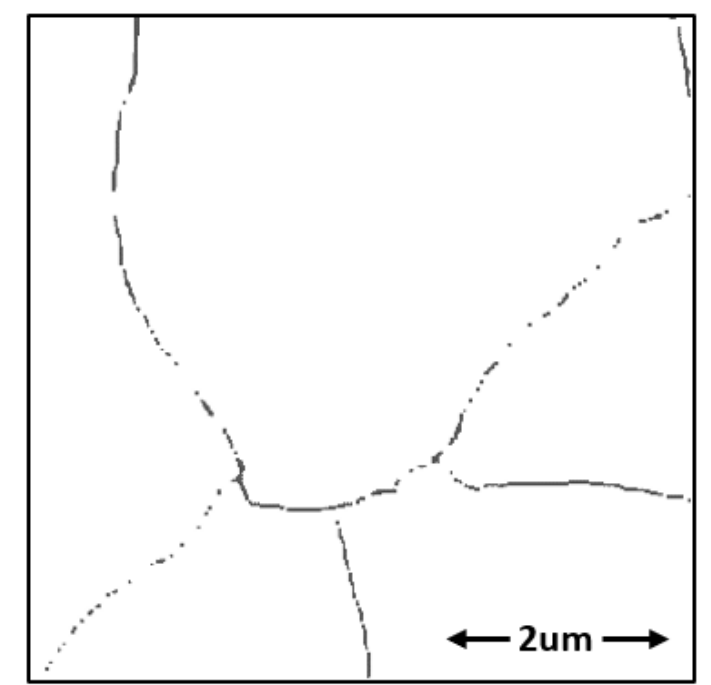

b)

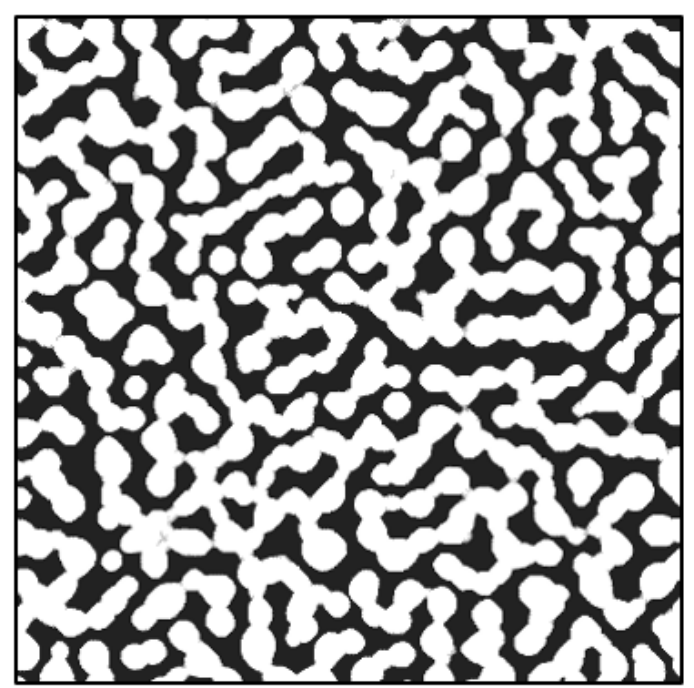

d)

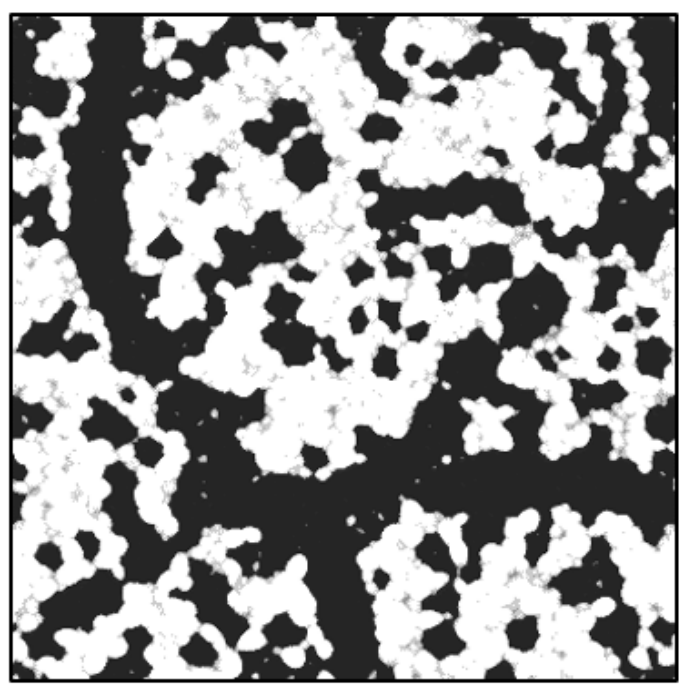

Figure 5 - Simulation of the Ni film evolution according to the surface diffusion model ( $a$ and $b$ ) and the fast diffusion model (c and d). a) Initial microstructure of a representative area of the nickel film; b) simulated microstructure evolved from a) by using the surface diffusion model; c) a slightly larger area of the initial nickel film; d) simulated microstructure evolved from $\mathrm{c}$ ) by using the fast diffusion model. The structures b) and d) refer to the result of the simulations when the nickel coverage is reduced to about $60 \%$, that is, in the proximity of the Ni percolation threshold. 


\section{Figure 6}

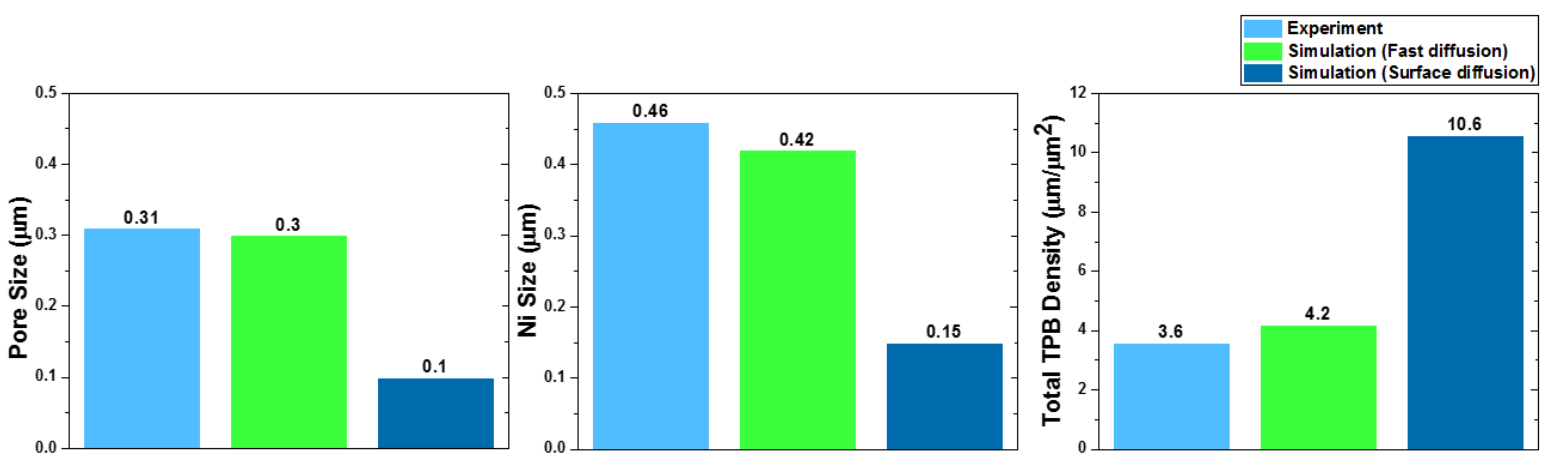

Figure 6 - Microstructural parameters (pore size, Ni size and TPB density) at the Ni percolation threshold obtained by different simulation models and evaluated in experimental E-SEM observations. In this graph, TPB values were calculated on a subset of the image area, thus they differ from those evaluated on the large dataset due to statistical variation. 


\section{Figure 7}
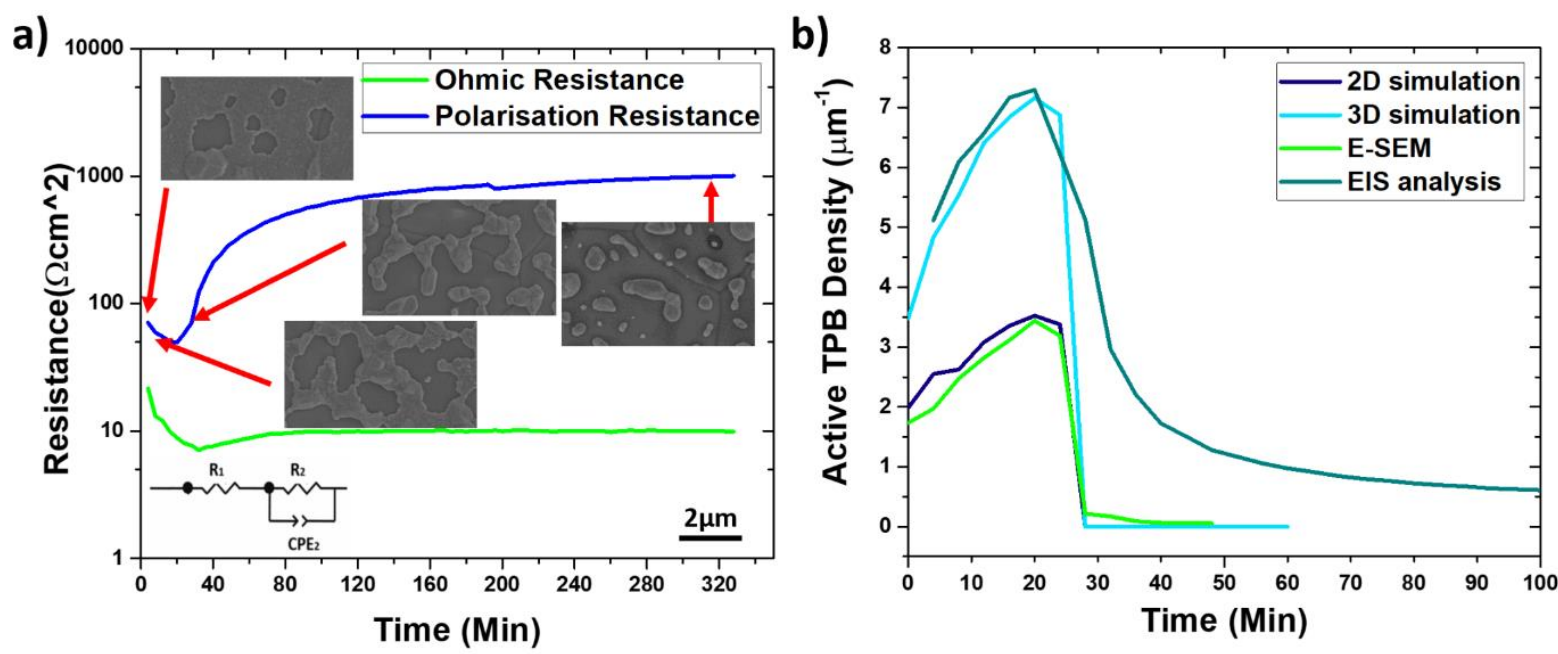

Figure 7 - Electrochemical degradation of the $\mathrm{Ni}$ film electrode as measured by EIS and correlation with the aTPB density. a) Ohmic resistance (green) and polarization resistance (blue) as a function of time as measured from impedance spectroscopy data at $600^{\circ} \mathrm{C}$ and $1 \mathrm{~atm}$. The insets show snapshots of the microstructural evolution at different times and the equivalent circuit used in EIS fitting. b) Active TPB density per unit of electrode area obtained from different methods: EIS analysis according to Equation (2) (dark green), analysis of experimental E-SEM images (light green), fast diffusion simulation for both 2D projection (dark blue) and 3D evaluation (light blue) of aTPBs. In b) time is normalized against the de-percolation time, equal to $22 \mathrm{~min}$ in experiments and to 550 time steps in the simulations. 


\title{
SUPPLEMENTARY MATERIAL
}

\section{Unveiling the Mechanisms of Solid-State Dewetting in Solid Oxide Cells with Novel 2D Electrodes}

\author{
B. Song, A. Bertei, X. Wang, S.J. Cooper, E. Ruiz-Trejo, R. Chowdhury, R. Podor, N.P. Brandon
}

Surface diffusion and fast diffusion models

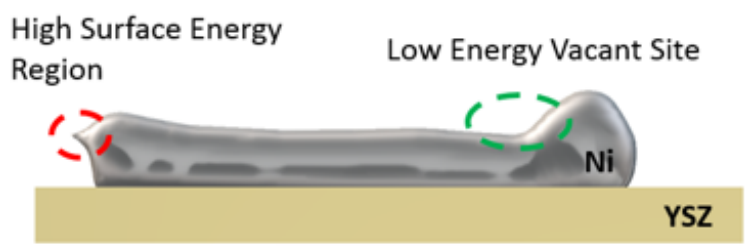

a)

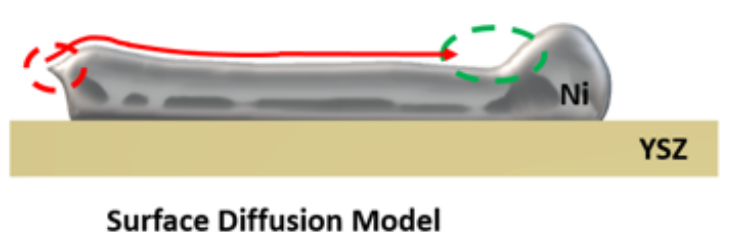

c) b)

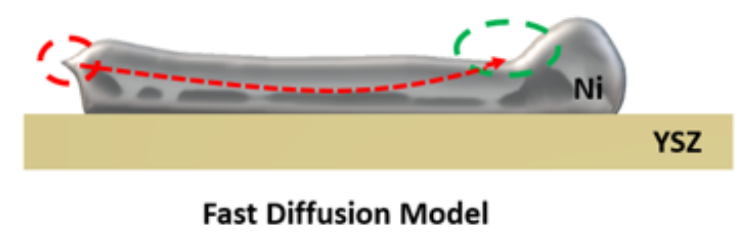

Initial state

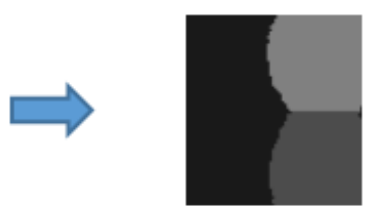

After $\mathbf{4 0 0}$ steps

Figure S1 - Schematic representation of surface diffusion and fast diffusion models. The figure shows a $\mathrm{Ni}$ cluster with a high surface energy region and low energy vacant site. a) According to the surface diffusion model, mass transport takes place along the surface, step-by-step, until the matter voxel reaches the low energy vacant site. b) According to the fast diffusion model, the high energy matter voxel can jump into the low energy vacant site in a single step. In both cases, mass transport takes place only within the same $\mathrm{Ni}$ cluster. c) Grain boundary migration model: each grain boundary voxel is allowed a chance of changing its state to that of one of its neighbors, with a probability proportional to the local energy difference: for example, at triple junction (within the red circle in $\mathrm{c}$ ), the energy of the voxels belonging to light grey and dark grey grains is higher than that of black grain. Therefore, these voxels, initially belonging to light grey and dark grey grains near triple grain junction, will be more likely to change their state to that of black grain. As a result, the triple junction will become more balanced at roughly $120^{\circ}$ after evolution (by assuming isotropic grain boundary energy). 


\section{Wire-based model}

Percolation across the full width of the imaged area was used to assess the global percolation of the nickel layer with the Pt mesh. If nickel percolated across the whole imaged area, the imaged active TPB density was assumed to be available to the entire electrode area. However, once Ni percolation from wire to image side stopped, the active TPB density was assumed to scale with the length of current collector mesh per unit area. Thus, the following equations were used: for Ni percolation across the whole imaged area:

$\rho_{\mathrm{aTPB}}=\frac{L_{\mathrm{aTPB}}}{A_{\text {image }}}$

and once Ni percolation was lost from the fictitious wire location to the image side:

$\rho_{\mathrm{aTPB}}=\frac{L_{\mathrm{aTPB}}}{L_{\text {wire-micro }}} \times \frac{L_{\text {wire-macro }}}{A_{\text {cell }}}$

where $\rho_{\text {aTPB }}$ is the active TPB density per unit of total cell area, $L_{\text {aTPB }}$ is total active TPB length, $A_{\text {image }}$ is the area of the imaged region, $L_{\text {wire-micro }}$ is the height of the imaged areas in Figure 1 (i.e., the assumed length of the current collector wire observed in this area), $L_{\text {wire-macro }}$ is the total Pt current collector length over the whole cell and $A_{\text {cell }}$ is the total cell area. As such, the first ratio on the right-hand side of Eq. (S2) gives a dimensionless aTPB length per unit length of current collector wire, while the second term is the expected wire length per total cell area. 
a)
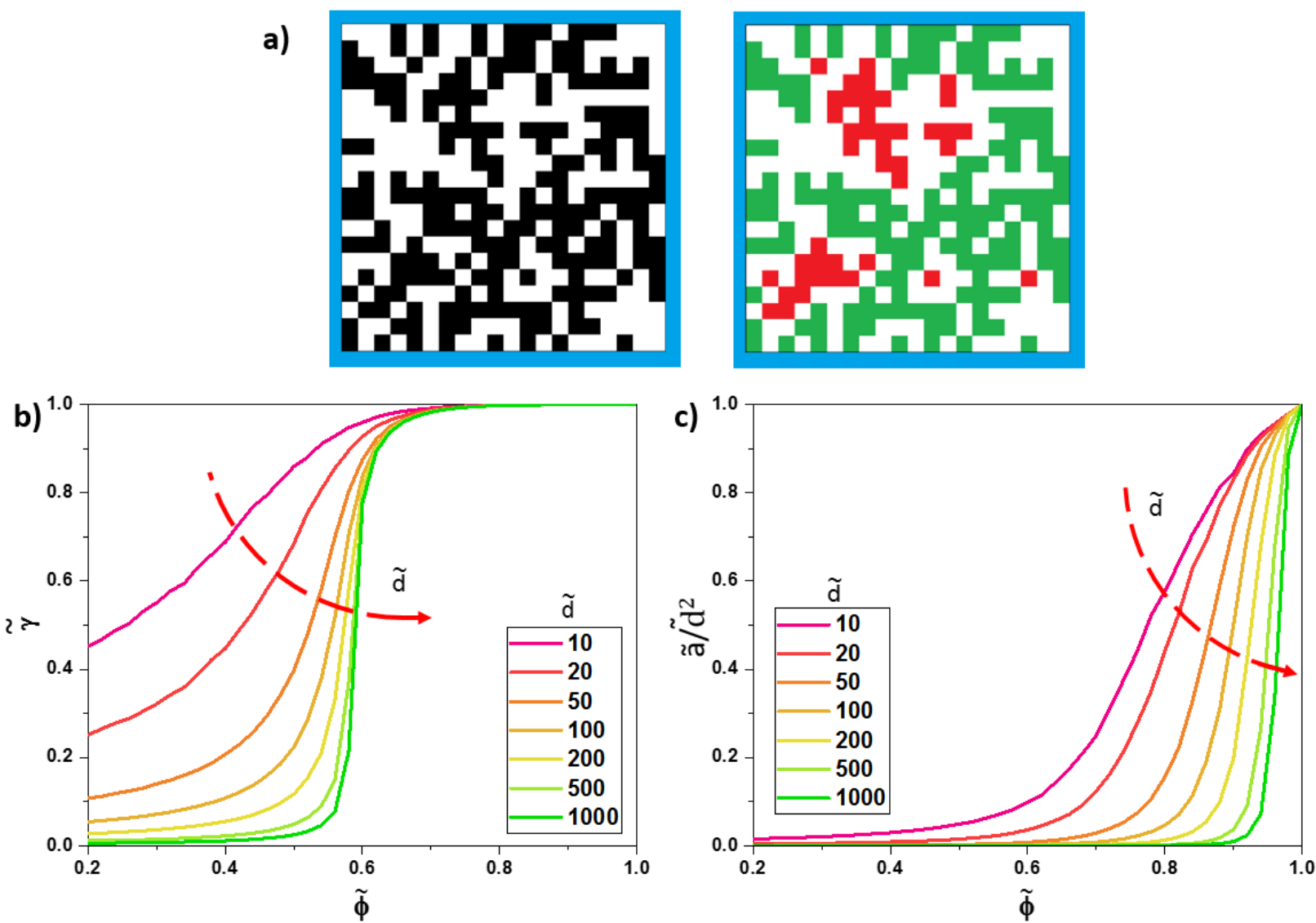

Figure S2 - Lattice-based model. a) Random realization of a square lattice (left), with clusters of green pixels connected to the external boundaries and isolated red clusters (right). In this context, a cluster represents a collection of pixels connected each other via one of the four pixel sides (but not through the pixel corners). In this specific case: $\tilde{d}=20$ (side length of the square lattice counted in pixels), $\tilde{\phi}=0.5$ (coverage fraction), $\tilde{a}=200 / 26 \approx 7.69$ (mean cluster area), $\tilde{\gamma}=159 / 200=0.795$ (percolation fraction). b) Percolation fraction $\tilde{\gamma}$ as a function of coverage fraction $\tilde{\phi}$ for different side lengths $\tilde{d}$. c) Normalized mean cluster area $\tilde{a} / \tilde{d}^{2}$ as a function of coverage fraction $\tilde{\phi}$ for different side lengths $\tilde{d}$.

Calculation of parameters in random lattice simulations (see Figure S2a), where a cluster in this context corresponds to a distinct particle in real E-SEM images:

$\tilde{\phi}=\frac{\# \text { black pixels }}{\tilde{d}^{2}}$

$\tilde{a}=\frac{\# \text { black pixels }}{\text { \# black clusters }}$

Eq. (S4)

$\tilde{\gamma}=\frac{\# \text { green pixels }}{\# \text { black pixels }}$ 


\section{Atomic Force Microscope}
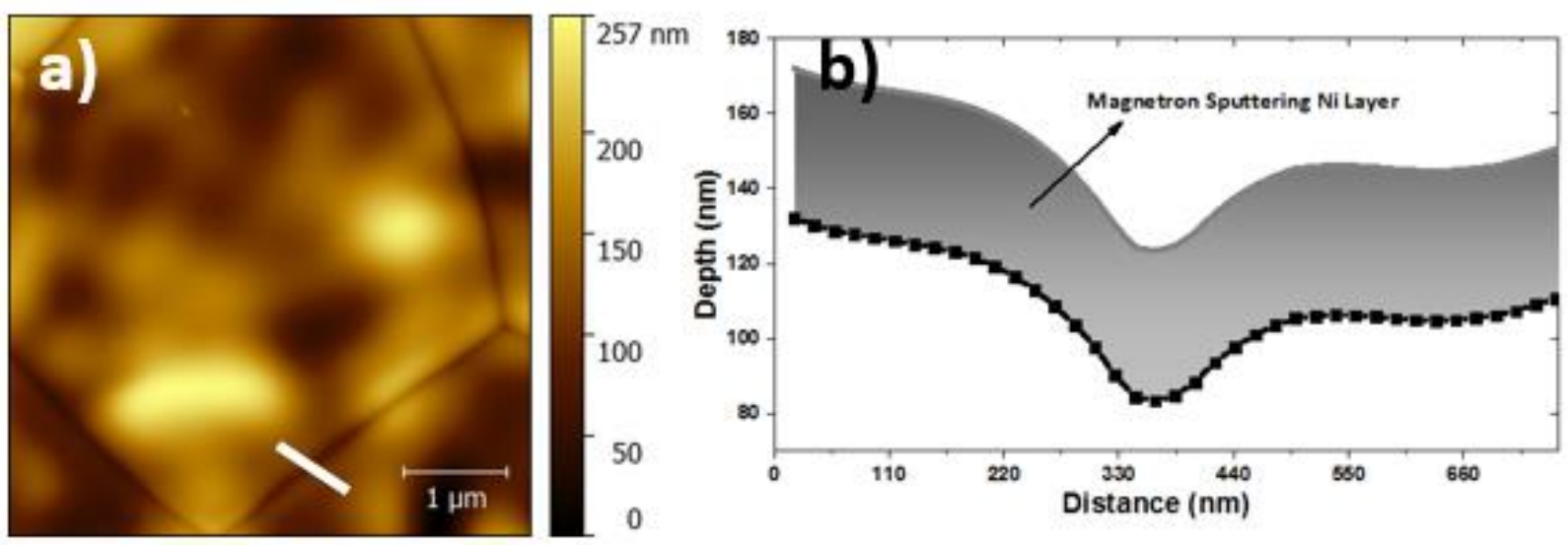

Figure S3 - Surface roughness and grain depth of the YSZ substrate measured by AFM. a) Map of the YSZ surface as measured before Ni deposition. b) Depth of the YSZ grain boundary measured along the line shown in a). A fictitious nickel layer of $40 \mathrm{~nm}$ is also presented in b).

\section{Dihedral angle}

Dihedral angle $=360^{\circ}$ - Observed grain contact angle
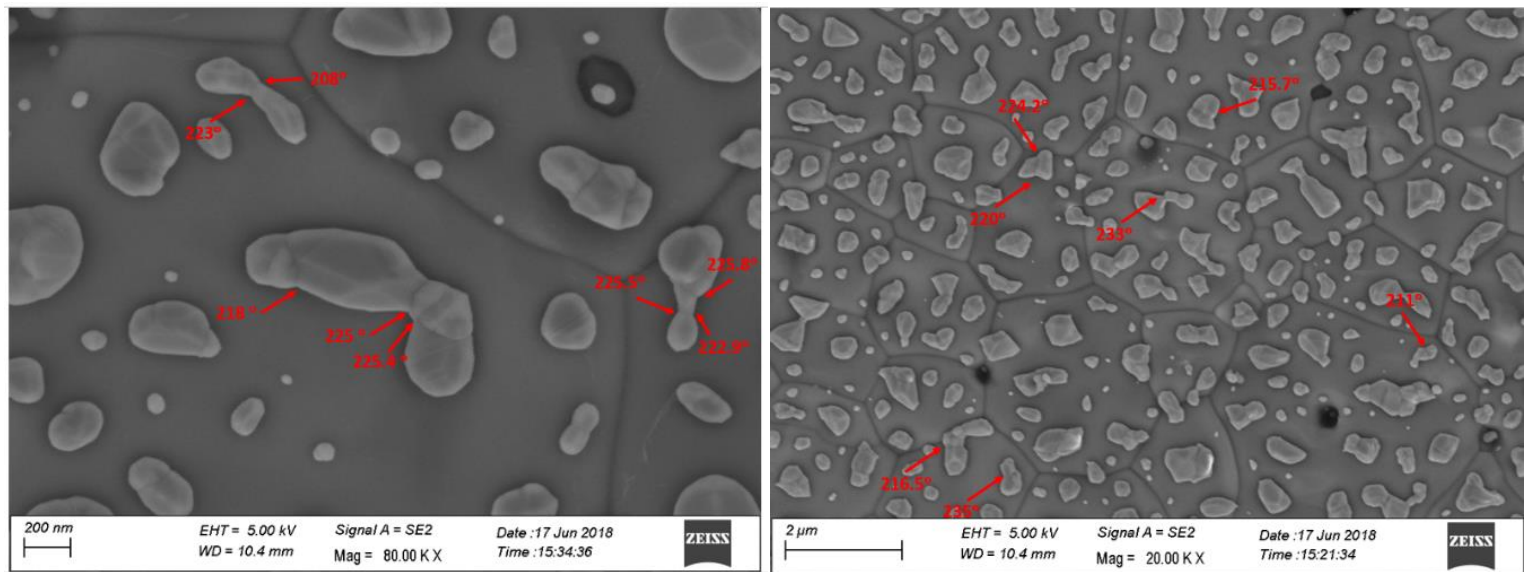

Figure S4 - SEM images of a dewetted Ni film on YSZ after degradation at $600{ }^{\circ} \mathrm{C}$, with dihedral angle measurements. Dihedral angle $=152^{\circ} \pm 7^{\circ}$.

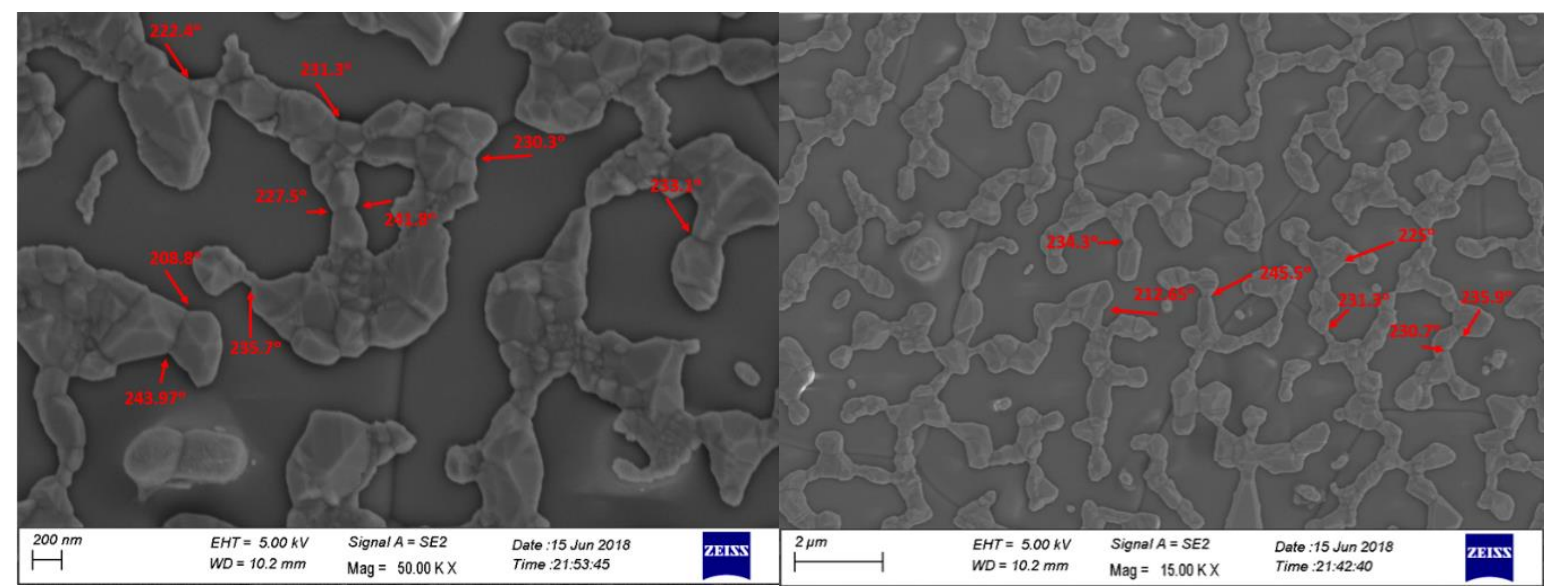

Figure S5 - SEM images of a dewetted Ni film on YSZ after degradation at $500{ }^{\circ} \mathrm{C}$, with dihedral angle measurements. Dihedral angle $=129^{\circ} \pm 10^{\circ}$. 

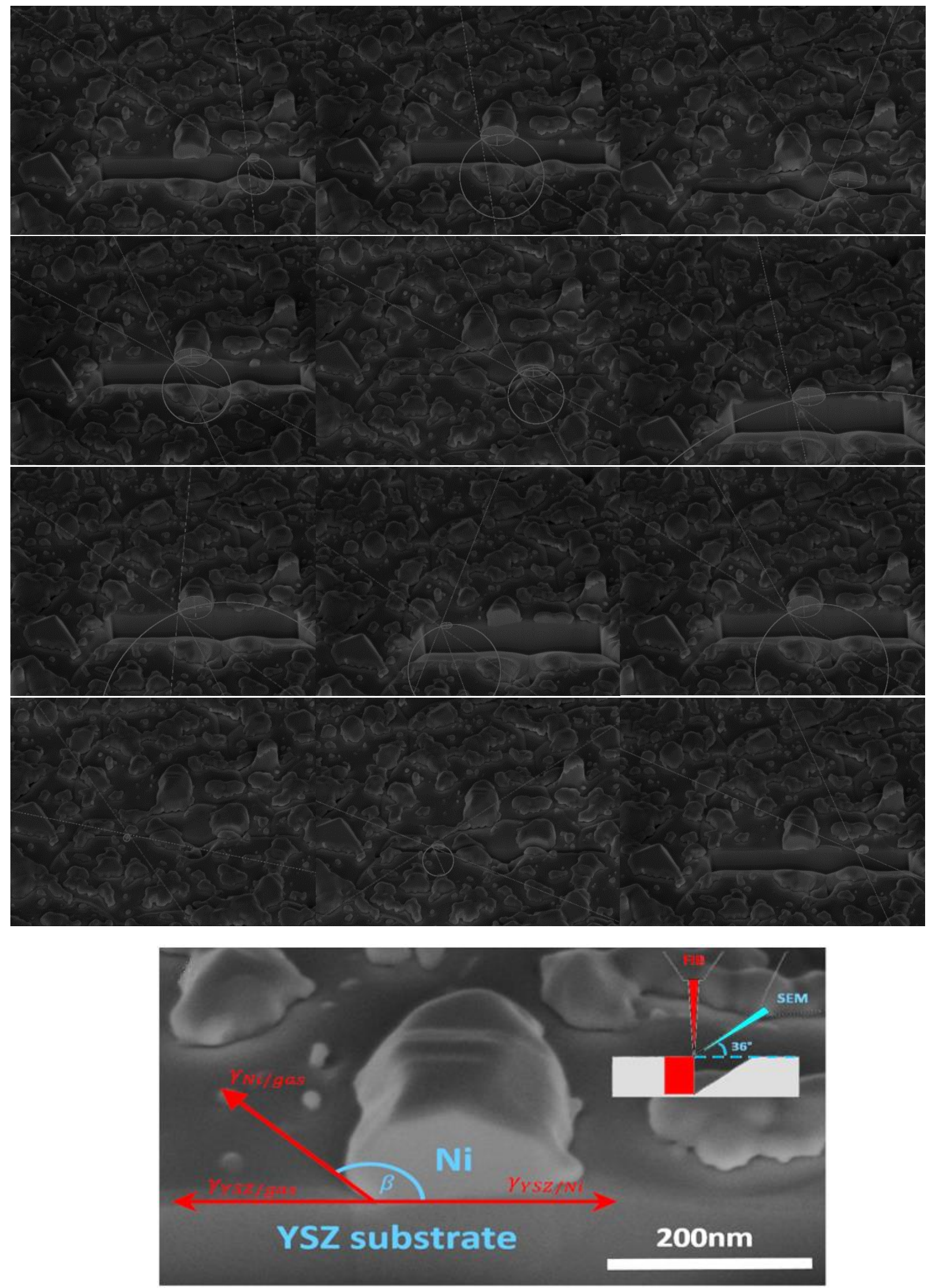

Figure S6 - FIB-SEM cross-sectional images for Ni wetting angle measurements. 
The wetting angle of nickel particles was measured with FIB-SEM cross-sectional views by considering $30 \mathrm{Ni}$ isolated particles with TPBs laying as perpendicularly as possible to the FIB-SEM cross-section plane. A wetting angle correction was considered due to the sample tilt of $54^{\circ}$ of the FIB milling direction. Here $\alpha$ is the real wetting angle, $\beta$ is the observed angle from SEM images. The contact point is a cross-section of a TPB (i.e., the intersection of gas/Ni/YSZ). From the SEM image, $\beta=126^{\circ} \pm 13^{\circ}$; therefore, after correction via Eq. (S6), the contact angle results equal to $\alpha=121^{\circ} \pm 12^{\circ}$, where the \pm symbol refers to the range of maximum/minimum values, taking into account both the statistical variation of the wetting angle and the errors introduced by the measurement procedure.

$\alpha=\arctan \left(\frac{\tan \beta}{\cos \left(36^{\circ}\right)}\right) \quad$ Eq. (S6)

\section{Dewetting at $800^{\circ} \mathrm{C}$ (late stage)}

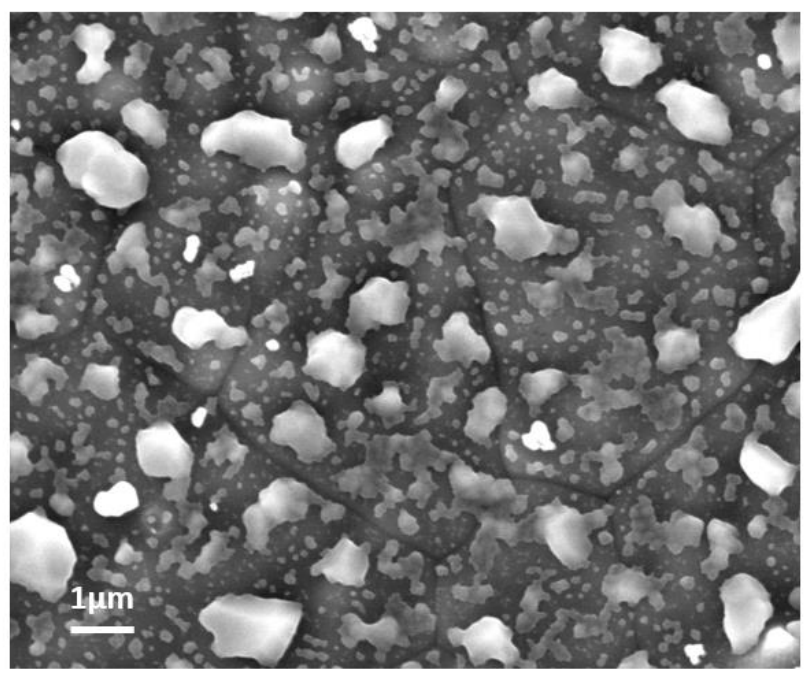

Figure S7 - Late stage dewetting of $40 \mathrm{~nm}$ nickel thin film at $800^{\circ} \mathrm{C}$, showing stable nickel nanoparticles disconnected from large clusters. The stability of nickel nanoparticles indicates that evaporationcondensation mechanism is not the dominant mass transport process. In fact, should the evaporationcondensation mechanism be significant, isolated Ni particles should have disappeared after annealing.

\section{XRD analysis}

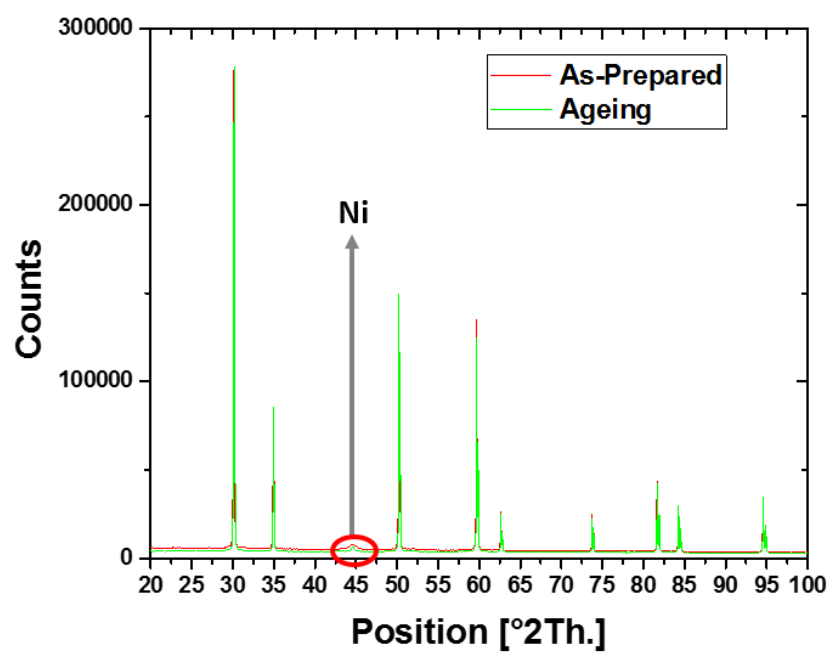

Figure S8 - XRD of as-prepared and aged $40 \mathrm{~nm} \mathrm{Ni}$ thin film on YSZ substrate. The indicated peak is from Ni, all the other peaks are due to YSZ. 


\section{Supporting videos}

The following supporting videos can be downloaded at the link:

https://doi.org/10.5281/zenodo.2546395

Video 1: an illustration of wire-based model for aTPB analysis.

Video 2: high magnification (x10000) video for $40 \mathrm{~nm}$ nickel thin film dewetting at $560^{\circ} \mathrm{C}$.

Video 3: high magnification (x10000) video for $40 \mathrm{~nm}$ nickel thin film dewetting at $600{ }^{\circ} \mathrm{C}$.

Video 4: nickel densification process during system heating up.

Video 5: low magnification (x5000) video for $40 \mathrm{~nm}$ nickel thin film dewetting at $560{ }^{\circ} \mathrm{C}$.

Video 6: low magnification (x5000) videos for $40 \mathrm{~nm}$ nickel thin film dewetting at $600{ }^{\circ} \mathrm{C}$.

Video 7: surface diffusion simulation for nickel dewetting process.

Video 8: fast diffusion simulation for nickel dewetting process. 